\title{
Iodine-mediated coastal particle formation: an overview of the Reactive Halogens in the Marine Boundary Layer (RHaMBLe) Roscoff coastal study
}

\author{
G. McFiggans ${ }^{1}$, C. S. E. Bale ${ }^{2}$, S. M. Ball ${ }^{3}$, J. M. Beames ${ }^{4}$, W. J. Bloss ${ }^{2, *}$, L. J. Carpenter ${ }^{5}$, J. Dorsey ${ }^{1,7}$, R. Dunk ${ }^{5}$, \\ M. J. Flynn ${ }^{1}$, K. L. Furneaux ${ }^{2, \dagger}$, M. W. Gallagher ${ }^{1}$, D. E. Heard ${ }^{2}$, A. M. Hollingsworth ${ }^{3}$, K. Hornsby ${ }^{5}$, T. Ingham ${ }^{2}$, \\ C. E. Jones ${ }^{5}$, R. L. Jones ${ }^{6}$, L. J. Kramer ${ }^{3}$, J. M. Langridge ${ }^{6}$, C. Leblanc ${ }^{8}$, J.-P. LeCrane ${ }^{6}$, J. D. Lee ${ }^{5,9}$, R. J. Leigh ${ }^{3}$, \\ I. Longley ${ }^{1}$, A. S. Mahajan ${ }^{2}$, P. S. Monks ${ }^{3}$, H. Oetjen ${ }^{2}$, A. J. Orr-Ewing ${ }^{4}$, J. M. C. Plane ${ }^{2}$, P. Potin ${ }^{8}$, A. J. L. Shillings ${ }^{6}$,

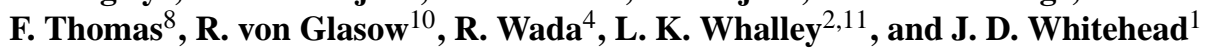 \\ ${ }^{1}$ Centre for Atmospheric Sciences, School of Earth, Atmospheric \& Environmental Sciences, University of Manchester, \\ Manchester, M13 9PL, UK \\ ${ }^{2}$ School of Chemistry, University of Leeds, Leeds, LS2 9JT, UK \\ ${ }^{3}$ Department of Chemistry, University of Leicester, Leicester, LE1 7RH, UK \\ ${ }^{4}$ School of Chemistry, University of Bristol, Bristol, BS8 1TS, UK \\ ${ }^{5}$ Department of Chemistry, University of York, Heslington, York, YO10 5DD, UK \\ ${ }^{6}$ Department of Chemistry, University of Cambridge, Lensfield Road, Cambridge, CB2 1EW, UK \\ ${ }^{7}$ National Centre for Atmospheric Sciences, University of Manchester, Manchester, M13 9PL, UK \\ ${ }^{8}$ Station Biologique, Université Pierre et Marie Curie-Paris 6 CNRS UMR 7139, Roscoff, France \\ ${ }^{9}$ National Centre for Atmospheric Sciences, University of York, Heslington, York, YO10 5DD, UK \\ ${ }^{10}$ School of Environmental Sciences, University of East Anglia, Norwich, Norfolk, NR4 7TJ, UK \\ ${ }^{11}$ National Centre for Atmospheric Sciences, University of Leeds, Leeds, LS2 9JT, UK \\ *now at: School of Geography, Earth Environmental Sciences, Univ. of Birmingham, Edgbaston, Birmingham, B152TT, UK \\ ${ }^{\dagger}$ sadly passed away 28 July 2009
}

Received: 23 October 2009 - Published in Atmos. Chem. Phys. Discuss.: 10 December 2009

Revised: 25 February 2010 - Accepted: 23 March 2010 - Published: 29 March 2010

\begin{abstract}
This paper presents a summary of the measurements made during the heavily-instrumented Reactive Halogens in the Marine Boundary Layer (RHaMBLe) coastal study in Roscoff on the North West coast of France throughout September 2006. It was clearly demonstrated that iodinemediated coastal particle formation occurs, driven by daytime low tide emission of molecular iodine, $\mathrm{I}_{2}$, by macroalgal species fully or partially exposed by the receding waterline. Ultrafine particle concentrations strongly correlate with the rapidly recycled reactive iodine species, IO, produced at high concentrations following photolysis of $I_{2}$. The heterogeneous macroalgal $\mathrm{I}_{2}$ sources lead to variable relative concentrations of iodine species observed by path-integrated and in situ measurement techniques.
\end{abstract}

Apparent particle emission fluxes were associated with an enhanced apparent depositional flux of ozone, consistent with both a direct $\mathrm{O}_{3}$ deposition to macroalgae and involvement of $\mathrm{O}_{3}$ in iodine photochemistry and subsequent particle formation below the measurement height. The magnitude of the particle formation events was observed to be greatest at the lowest tides with the highest concentrations of ultrafine particles growing to the largest sizes, probably by the condensation of anthropogenically-formed condensable material. At such sizes the particles should be able to act as cloud condensation nuclei at reasonable atmospheric supersaturations.

\section{Correspondence to: G. McFiggans}

(g.mcfiggans@manchester.ac.uk)

Published by Copernicus Publications on behalf of the European Geosciences Union. 


\section{Introduction}

Research into marine atmospheric halogens has recently focused on two major implications: i) participation of reactive halogen species in catalytic ozone destruction cycles including heterogeneous reaction in or on seasalt aerosol and ii) the formation of new aerosol particles in the coastal boundary layer and their potential to act as cloud condensation nuclei $(\mathrm{CCN})$. Marine boundary layer (MBL) field measurements of reactive halogen species (RHS) have largely been made at coastal locations (most notably at Mace Head on the West coast of Ireland) and have identified both iodine- (e.g., Alicke et al., 1999; Allan et al., 2000; Saiz-Lopez and Plane, 2004; Peters et al., 2005) and bromine- (e.g., Saiz-Lopez et al., 2004; Peters et al., 2005) containing inorganic species. Whilst the primary source of inorganic chlorine and bromine species in the remote MBL is likely to be their release from the significant seasalt halide reservoir in atmospheric aerosol, the direct emission of organic precursors (Carpenter et al., 1999, 2000) from intertidal macroalgal species (Palmer et al., 2005) has been well established and will contribute significantly to the coastal atmospheric burden of RHS. Halocarbons (particularly iodocarbons) were shown to exhibit a tidal signature, with enhanced low tide abundances. This might be expected following macroalgal exposure at low tide. The most widely-observed coastal inorganic RHS, iodine monoxide (IO), has also consistently been shown to exhibit a tidal signature, but only during daytime, consistent with photochemical formation of IO. A causal linkage between the tidally varying iodocarbon and IO concentrations was hypothesised and explored by Carpenter et al. $(1999,2001)$ and McFiggans et al. (2000); the last study invoking iodine cycling through seasalt aerosol as first described by Vogt et al. (1999). Atomic iodine, I, released by photolabile precursors reacts with available $\mathrm{O}_{3}$ to yield IO, rapidly establishing a photostationary state and consuming $\mathrm{O}_{3}$ whenever IO reacts either with itself, $\mathrm{HO}_{2}$ or $\mathrm{NO}_{2}$, rather than being re-photolysed to release I atoms. The self-reaction of IO yields OIO; the reaction with $\mathrm{HO}_{2}$ and $\mathrm{NO}_{2}$ yielding $\mathrm{HOI}$ and $\mathrm{IONO}_{2}$ respectively. The latter two compounds may be taken up by aerosol particles, releasing the dihalogen species $\mathrm{IBr}, \mathrm{ICl}$ or $\mathrm{I}_{2}$ on aqueous reaction with available $\mathrm{Br}^{-}, \mathrm{Cl}^{-}$or $\mathrm{I}^{-}$respectively in the presence of sufficient acidity.

In addition to the tidal halogen cycling, studies at Mace Head revealed the rapid appearance of high concentrations of ultrafine aerosol particles (O'Dowd et al., 1999, 2002a, and references therein) at daytime low tide. Should even a small fraction of the particles grow sufficiently large that they would act as $\mathrm{CCN}$ at supersaturations corresponding to updraughts in typical marine stratocumulus clouds, such particle formation may significantly impact on local and regional radiative forcing. During both long-term and intensive measurements in the Particle Formation in the Coastal Environment (PARFORCE) project, O'Dowd et al. (2002a) reported consistent observations of clear and abrupt increases in the number concentration of particles between $3 \mathrm{~nm}$ and $10 \mathrm{~nm}$ diameter with a daytime low tidal signature and particles formed on $90 \%$ of the days. Particle formation was classified by air mass into four categories (O'Dowd et al., 2002c) with characteristic behaviour in each. Dal Maso et al. (2002) derived new particle growth rate, estimated $1 \mathrm{~nm}$ cluster concentration and condensable vapour source rate from the combination of measurement and model application dependent on nucleation event category. Direct micrometeorological flux determinations (Flanagan et al., 2005) yielded particle number fluxes during bursts of $10^{9}$ to $10^{10} \mathrm{~m}^{-2} \mathrm{~s}^{-1}$ and noticed close correlation between concentration and net positive flux during single source events at Mace Head, potentially simplifying particle flux determination by concentration measurements under similar conditions at different locations.

In studies of laboratory particle formation from photooxidation of elevated (ppb) concentrations of $\mathrm{CH}_{2} \mathrm{I}_{2}$ in the presence of $\mathrm{O}_{3}$, Hoffmann et al. (2001) postulated that the observed mass spectrometric $\mathrm{IO}^{-}, \mathrm{IO}_{2}^{-}$and $\mathrm{IO}_{3}^{-}$fragments corresponded to polymers from the sequential addition of OIO to the initial diiodine tetraoxide $\left(\mathrm{I}_{2} \mathrm{O}_{4}\right)$ dimers. Given the low solubility of $\mathrm{I}_{2} \mathrm{O}_{4}$, this would be consistent with the reported low hygroscopicity of freshly formed particles probed at Mace Head (Väkevä et al., 2002). This mechanism was employed in a coupled chamber and modelling investigation of $\mathrm{CH}_{2} \mathrm{I}_{2}$ photo-oxidation (O'Dowd et al., 2002b; Jimenez et al., 2003) that revealed an aerosol mass spectrometer (AMS) fingerprint of the particles consistent with iodine oxides and oxy-acids and a particle structure consistent with fractal agglomerates that collapsed under increased humidity. Particle formation was found not to occur if any one of $\mathrm{CH}_{2} \mathrm{I}_{2}, \mathrm{O}_{3}$ or uv radiation were absent. Based on postulated OIO self-nucleation, the co-authors hypothesised that iodocarbon photolysis led to homogeneous nucleation by clustering of the resulting $\mathrm{I}_{2} \mathrm{O}_{4}$ and that enhancement of marine particle number could be sufficient to impact on global radiative forcing.

During the North Atlantic Marine Boundary Layer EXperiment (NAMBLEX) (Heard et al., 2006) at the same site, many of the linkages between iodine chemistry and new particle production were more firmly established in the ambient atmosphere. Saiz-Lopez and Plane (2004) reported, at significant mixing ratios, the first atmospheric observations of gaseous molecular iodine $\left(\mathrm{I}_{2}\right)$ using long-path (LP) differential optical absorption spectroscopy (DOAS) as well as confirming the previous tidal IO relationship. McFiggans et al. (2004) demonstrated the formation of particles from the reactions of ozone with emissions from the widespread macroalgal species Laminaria digitata and showed that $\mathrm{I}_{2}$ was a much greater coastal source of iodine than iodocarbons (furthermore, McFiggans, 2005, argued that only a similar source of iodine, much more photolabile than available iodocarbons, could provide sufficient atomic iodine to lead to particle formation in remote environments). The particles 
formed from the photooxidation of macroalgal emissions were identical in composition, morphology and hygroscopic behaviour to those formed in the photooxidation of $\mathrm{CH}_{2} \mathrm{I}_{2}$ and $\mathrm{I}_{2}$. Subsequent incubation investigations have further characterised the iodine compound release, ozone consumption and particle formation responses (Palmer et al., 2005) and elucidated the chemical nature $\left(\mathrm{I}^{-}\right)$and location of sequestered iodine (Küpper et al., 2008; Verhaeghe et al., 2008) and improved mechanistic understanding of biological iodine release. During NAMBLEX, in addition to the LP DOAS measurements, Broadband Cavity Ringdown Spectroscopy (BBCRDS) and Inductively Coupled Plasma/Mass Spectrometer (ICP/MS) measurements of $\mathrm{I}_{2}$ indicated that local "hot-spot" concentrations were significantly elevated above the path integrated values (Saiz-Lopez et al., 2006) and that $I_{2}$ correlated with low tide and the largest concentration of ultrafine particles.

There have been a number of modelling studies aiming to replicate the particle formation observed in field or laboratory systems. Burkholder et al. (2004) conducted laboratory measurements of particle formation in the photolysis of $\mathrm{CF}_{3} \mathrm{I}$ and $\mathrm{CH}_{2} \mathrm{I}_{2}$ in the presence of $\mathrm{O}_{3}$ and, in their model of the system, tuned the binding enthalpies of OIO according to cluster size to match the experimental data. The model was used to attempt to explain previously measured particle concentrations, concluding that the high IO concentrations that would be required for particle formation were in conflict with published long-path DOAS measurements of IO but were consistent with the hypothesis of localised hot-spots of high iodine emission. This was reinforced by the 1-D modelling study of Pechtl et al. (2006) where it was demonstrated that homogeneous nucleation of OIO was unable to support the measured particle concentrations at long-path measured IO concentrations. Furthermore it was predicted that OIO could only be responsible for growth, not nucleation, of particles in polluted air advected over iodine hotspots because of the strong suppression of IO by reaction with $\mathrm{NO}_{2}$ and of OIO by reaction with NO. Rather than assuming OIO dimerisation to be the initial nucleation step, Saiz-Lopez et al. (2006) used a model allowing clustering of all iodine oxides beyond IO (and condensation of all including IO) to explain observations during NAMBLEX of iodine species and ultrafine particles. They clearly confirmed that molecular iodine, $\mathrm{I}_{2}$, rather than organic iodine-containing compounds was the source of gaseous reactive iodine and very likely of new particles and that the majority of the $\mathrm{I}_{2}$ was located in a very narrow strip comprising only $8 \%$ of the $4.2 \mathrm{~km}$ DOAS light path. This was consistent with the BBCRDS and ICP/MSmeasured "hot-spot" $I_{2}$ concentrations. A modelling study driven by the $\mathrm{I}_{2}$ emissions and sequential condensation of higher iodine oxides was able to reproduce the observed particle bursts and demonstrate that they could contribute to the regional ambient cloud condensation nucleus $(\mathrm{CCN})$ burden, hence affecting radiative forcing as previously postulated.
As summarised above, all previous field studies relating iodine photochemistry to coastal particle bursts have been conducted at Mace Head. This manuscript introduces measurements made during the coastal study within the NERC UK SOLAS-funded Reactive Halogens in the Marine Boundary Layer (RHaMBLe) programme in Roscoff, Brittany, and analyses based on these measurements to resolve outstanding questions in the iodine-mediated coastal formation of new particles. Further contributions to this special issue provide fuller descriptions of these investigations. The three main goals of the RHaMBLe coastal study were to investigate:

(i) whether the coastal particle burst phenomenon is more general than that observed at Mace Head,

(ii) whether any such bursts exhibit a daytime low tidal signature and

(iii) whether there was a similar relationship with iodine photochemistry.

In the expectation that such relationships would be demonstrated, the intention was to conduct a full characterisation of the organic and inorganic iodine precursors, coastal photochemistry and the iodine-mediated particle formation. With the unique deployment of path-integrated and in situ instrumentation a comparison between the iodine-mediated particle formation on the north coast of Brittany and the west coast of Ireland could be made.

\section{Experiment location}

Roscoff, a coastal town in Brittany in the north-west of France as shown in the top left panel of Fig. 1, was chosen for the RHaMBLe coastal study for a number of reasons.

(i) Extensive previous characterisation of the ecosystems along the coastline indicated the likelihood of a significant flux of iodine through active macroalgal metabolism (the overlay in the central panel of panel of Fig. 1 shows the distribution of macroalgal species in the immediate vicinity of Roscoff).

(ii) The tidal range at Roscoff is large and would result in a significant intertidal exposure of macroalgae owing to the very wide littoral zone (this may be appreciated by considering the bathymetry contours in the overlay in the central panel of Fig. 1).

(iii) Proximity to significant infrastructure at the CNRS Station Biologique (SBR) and the town of Roscoff was able to provide adequate support for a large-scale field deployment.

The measurements were conducted near to the SBR, during September 2006. An extensive array of instrumentation for in situ measurements was located on a solid flat paved 


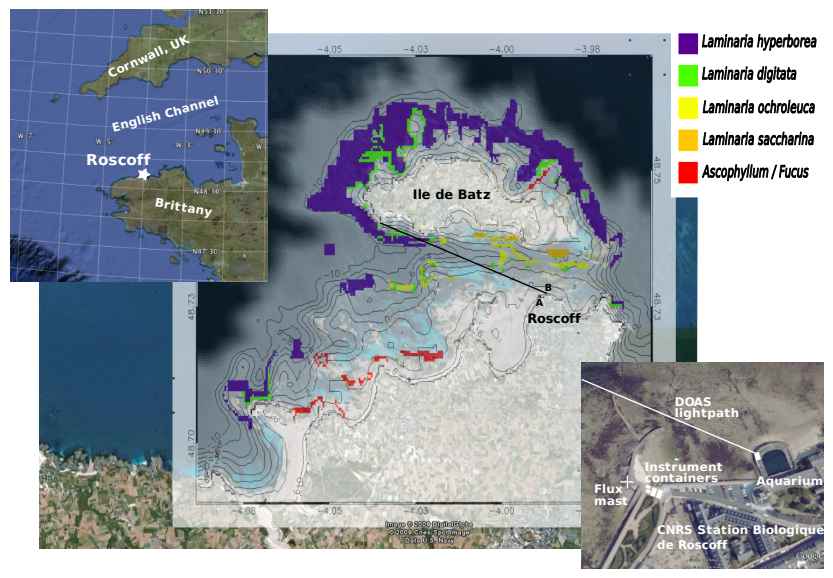

Fig. 1. The top left panel shows the location of Roscoff on the Northwest coast of Brittany. The main panel shows an aerial image of the local coastline with an overlay showing the speciated macroalgal distribution and bathymetry contours. Also marked are the locations of the in situ concentration and flux measurements (A) and the housing of the DOAS telescope (B) from which the lightpath extended across to the Southwest of Île de Batz. The bottom right panel shows a higher resolution aeriel view of the measurement site

area at the shore side convex apex of the road outside SBR $\left(48^{\circ} 43^{\prime} 37^{\prime \prime} \mathrm{N}, 3^{\circ} 59^{\prime} 20^{\prime \prime} \mathrm{W}\right)$ with a flux mast on the adjacent low stone jetty and the DOAS telescope located outside the SBR aquarium building $\left(48^{\circ} 43^{\prime} 38.5^{\prime \prime} \mathrm{N}, 3^{\circ} 59^{\prime} 15^{\prime \prime} \mathrm{W}\right)$. Halocarbon measurements were made in air continuously sampled from close to the in situ instruments and drawn down sample lines to the GC-MS instrumentation located in the SBR building. The bottom right panel of Fig. 1 outlines the relative placement of the instrumentation.

The measurement location provided a fetch of at least $800 \mathrm{~m}$, and up to $3 \mathrm{~km}$, over the littoral zone and shallow offshore waters for a wind direction of between $215^{\circ}$ and $005^{\circ}$. The maximum tidal range at this site is $9.6 \mathrm{~m}$, revealing extensive macroalgae beds in the broader fetch at low tide (see Sect. 2.2). More broadly, the location of Roscoff ensures that airmasses from all wind sectors passes over exposed tidal regions within tens of kilometers of the measurement site.

\section{Macroalgal distribution}

The Roscoff inter-tidal zone in front of the SBR extends more than five kilometers in length and about $1 \mathrm{~km}$ in width. Immediately in front of the SBR, the very shallow inter-tidal zone results in water closest to the shoreline being too shallow for Laminaria spp. (kelps) and in the direct vicinity of the SBR, the patchy distribution of seaweed species is mainly dominated by Fucus spp. (fucoids) and Ascophyllum beds. There is a small amount of Laminaria digitata, Saccharina latissima and Laminaria ochroleuca in the channel and tidal pools between the site and Île de Batz, a small island north of Roscoff. Shallow patchy rocky habitats surrounded by sand and gravel and covered by fucoids extend along the sheltered south shore of Île de Batz. Kelp beds (mainly of L. hyperborea) are present to the north of Île de Batz and L. digitata is most prevalent in quite exposed areas or at sites with strong water currents around the small islands off the Perharidy peninsula and to the west of the Ile de Batz, to the north-east of the Île de Batz, and in rockpools up to mid-tide level and higher on wave-exposed coasts of the Île de Batz.

The vertical zonation and the driving forces behind the macroalgal distribution are further discussed in Leigh et al. (2009). The previous work to map the macroalgal distribution (Braud, 1974; Bajjouk et al., 1996) in the vicinity of Roscoff has been used as the basis for the new evaluated digitised map presented and used for the $\mathrm{I}_{2}$ source modelling in Leigh et al. (2009) and used as the overlay in the central panel of panel of Fig. 1 .

\section{Methodology and techniques}

A comprehensive suite of instrumentation was deployed in order to characterise, so far as possible, all chemical species and physical factors thought to play a determinant role in the photochemical particle formation. Table 1 lists the instrumentation deployed during the RHaMBLe Roscoff deployment.

\subsection{Gaseous component concentration measurements}

A broad range of techniques were applied to characterise gaseous closed-shell and radical species:

\subsubsection{Path-integrated spectroscopic techniques}

Long Path-DOAS (Plane and Saiz-Lopez, 2006) was used to measure the concentrations of $\mathrm{I}_{2}, \mathrm{OIO}, \mathrm{IO}, \mathrm{BrO}, \mathrm{NO}_{2}$ and $\mathrm{NO}_{3}$. The DOAS instrument is fully-described in Saiz-Lopez and Plane (2004). Briefly, the instrument comprises a 450W xenon lamp at the focal point of a $32 \mathrm{~cm}$ diameter Newtonian telescope, producing a collimated beam which is directed towards a retroreflector array. The absorption path extended $3.35 \mathrm{~km}$ from the telescope located in a temporary housing outside the aquarium wall of SBR (bottom right panel in Fig. 1) to the retroreflector array located on an outcrop on the SW of Île de Batz $\left(48^{\circ} 44^{\prime} 24^{\prime \prime} \mathrm{N}, 4^{\circ} 2^{\prime} 10^{\prime \prime} \mathrm{W}\right)$. The total optical path length was $6.7 \mathrm{~km}$ and the beam was 7 to $12 \mathrm{~m}$ above the mean sea level. The returning light was captured by the same telescope and dispersed through a $0.5 \mathrm{~m}$ Czerny-Turner spectrometer with a 1200 grooves $\mathrm{mm}^{-1}$ grating, producing a spectral resolution of $0.25 \mathrm{~nm}$ over a range of $\sim 40 \mathrm{~nm}$ on a 1024-element CCD camera. Spectra were recorded with $0.25 \mathrm{~nm}$ resolution before being converted into differential optical density using a Fast Fourier Transform (FFT) and the 
Table 1. Measurement and instrument listing for the RHaMBLe Roscoff experiment in September 2006.

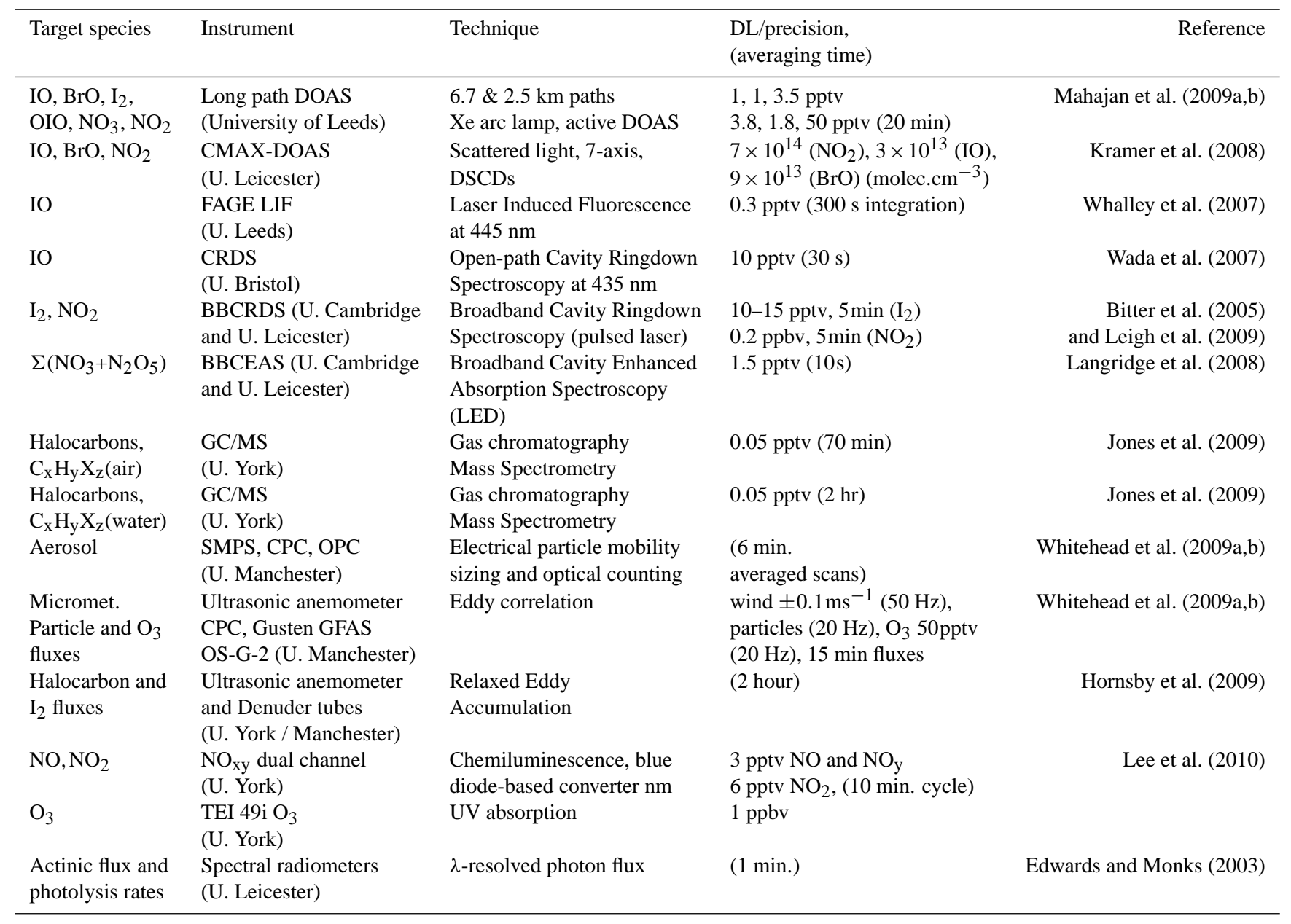

contributions of individual species determined by simultaneous fitting their absorption cross-sections using singular value decomposition (Plane and Saiz-Lopez, 2006). During the day, the instrument was run on either the $\mathrm{I}_{2} / \mathrm{OIO}, \mathrm{BrO}$ or IO spectral regions, while $\mathrm{NO}_{3}$ was measured at night. Further instrumentation details and a comprehensive description of the iodine species and $\mathrm{BrO}$ measurements are given in Mahajan et al. (2009a) and Mahajan et al. (2009b) respectively. $\mathrm{I}_{2}, \mathrm{OIO}, \mathrm{IO}$ and $\mathrm{BrO}$ measurements are summarised in Sect. 6.3; $\mathrm{NO}_{3}$ and $\mathrm{NO}_{2}$ measurements are presented in Sect. 6.1.

A Concurrent Multi-Axis DOAS (CMAX-DOAS) instrument was deployed to measure the Differential Slant Column Density (DSCD) of absorbing gaseous species at multiple viewing angles using scattered light. The head of the unit was located on top of a mast approximately $5 \mathrm{~m}$ above the ground, fixed to the side of the most Westerly container. In addition to five telescopes incorporated into the head unit pointing north at elevation angles of $2^{\circ}, 5^{\circ}, 10^{\circ}, 15^{\circ}$, and $90^{\circ}$ (zenith), two telescopes were attached to the side of the unit. One of the telescopes was permanently fixed at an elevation of $5^{\circ}$ and an azimuth angle of $60^{\circ}$ west. The second was originally used as an additional zenith view as a self-consistency test for the instrument, but was relocated and permanently fixed at an elevation angle of $5^{\circ}$ and $60^{\circ}$ east. Fibres from each telescope were connected via a multi-track fibre to an imaging spectrometer (Oriel MS257), with spectra concurrently imaged on a CCD detector. For IO a retrieval window from 434 to $449 \mathrm{~nm}$ was applied, to include three absorption bands of IO at 436, 445 and $456 \mathrm{~nm}$; for $\mathrm{BrO}$ a wavelength window of $23 \mathrm{~nm}$ from 341 to $364 \mathrm{~nm}$ was used to include four $\mathrm{BrO}$ bands. Absorptions by $\mathrm{O}_{3}, \mathrm{NO}_{2}$, the oxygen dimer $\mathrm{O}_{4}$ and water vapour were also included in the DOAS fitting routine for both retrieval fitting windows. Owing to instrument problems, a slightly degraded performance was experienced in this experiment such that detection limits of approximately $3 \times 10^{13}$ molecules $\mathrm{cm}^{-2}$ for IO, $9 \times 10^{13}$ molecules $\mathrm{cm}^{-2}$ for $\mathrm{BrO}$ and $7 \times 10^{14}$ molecules $\mathrm{cm}^{-2}$ for the $\mathrm{NO}_{2}$ DSCD were achieved. A detailed description of the instrument can be found in Leigh et al. (2006); Kramer et al. (2008). 


\subsubsection{Measurements by Laser Induced Fluorescence (LIF)}

In situ measurements of IO by LIF were made for the first time during the RHaMBLe experiment. A full description of the instrument can be found in Whalley et al. (2007). Ambient air is sampled through a conical nozzle with a pinhole diameter of $0.8 \mathrm{~mm}$ (flow rate $=5 \mathrm{slm}$ ) into a LIF cell held at 150 Torr. Daily calibrations were performed to determine the instrument sensitivity. During RHaMBLe, the minimum online collection period was $10 \mathrm{~s}$. The sensitivity of the instrument decreased gradually throughout the campaign, which resulted in the instrument DL increasing by a factor of ten over the campaign. When the instrument was performing at its best the DL was 0.4 pptv over a $150 \mathrm{~s}$ integration period (defined by Whalley et al., 2007). The LIF IO instrument was located in the most easterly shipping container adjacent to the seawall and the small jetty at the edge of the town (bottom right panel of Fig. 1). The LIF cell was located on the roof of the shipping container with the inlet pinhole at a height of $3.5 \mathrm{~m}$ above ground level. At high tide the LIF cell was approximately $3.5 \mathrm{~m}$ from the waters edge. Further details of the instrumentation and measurements is provided in Furneaux et al. (2009) and the measurements are summarised in Sect. 6.3.

\subsubsection{Measurements by cavity-based spectroscopy}

A broadband cavity ringdown spectroscopy (BBCRDS) system was deployed from the Westerly of the two shipping containers on the jetty to measure in situ concentrations of $\mathrm{I}_{2}$. The BBCRDS instrument's operating principles are the same as those described in detail by Bitter et al. (2005) for the predecessor instrument that was used to detect ambient $\mathrm{I}_{2}$ (and other absorbers) during the NAMBLEX campaign at Mace Head in 2002 (Saiz-Lopez et al., 2006). The present instrument's performance has since been enhanced by a new broadband laser system and a new CCD (charge coupled device) detector and is described in more detail by Leigh et al. (2009). The retrieval precision was typically $10 \mathrm{pptv}$ for $\mathrm{I}_{2}$ and $0.2 \mathrm{ppbv}$ for $\mathrm{NO}_{2}(1 \sigma$ uncertainty, $304 \mathrm{~s}$ averaging time).

A broadband cavity enhanced absorption spectroscopy (BBCEAS) instrument was co-deployed from the same field container as the BBCRDS system. The BBCEAS instrument operated from 14 to 22 September and is described in detail by Langridge et al. (2008). For RHaMBLe, the $\mathrm{NO}_{3}$ absorption recorded by the BBCEAS instrument was the sum of ambient $\mathrm{NO}_{3}$ and $\mathrm{NO}_{3}$ produced from the thermolysis of ambient $\mathrm{N}_{2} \mathrm{O}_{5}$.

A further open-path cavity ringdown spectroscopy (CRDS) instrument was deployed for the first time to measure ambient IO concentrations. The instrument and analysis were reported in detail in Wada et al. (2007) and the instrument achieved a typical detection limit of 10 pptv at an inte- gration time of $30 \mathrm{~s}$, with some fluctuation depending on the wind and ambient aerosol loading.

\subsubsection{Mass spectrometric measurements}

Halocarbon concentrations in ambient air were measured continuously (new sample every $\sim 90 \mathrm{~min}, 24 \mathrm{~h}$ per day) between 3 and 27 September 2006, with only short breaks for calibration and instrument maintenance. The volatile halocarbons targeted were $\mathrm{CH}_{3} \mathrm{I}, \mathrm{C}_{2} \mathrm{H}_{5} \mathrm{I}, 1-\mathrm{C}_{3} \mathrm{H}_{7} \mathrm{I}, 2-\mathrm{C}_{3} \mathrm{H}_{7} \mathrm{I}$, $\mathrm{CH}_{2} \mathrm{ICl}, \mathrm{CH}_{2} \mathrm{IBr}$ and $\mathrm{CH}_{2} \mathrm{I}_{2}$, along with the brominated gases $\mathrm{CH}_{2} \mathrm{Br}_{2}$ and $\mathrm{CHBr}_{3}$ and their concentrations were determined using an automated Perkin Elmer Turbomatrix gas chromatography-mass spectrometer (GC-MS). Calibrations were carried out as described by Wevill and Carpenter (2004), in addition to daily analysis of an in-house prepared gas standard to account for day-to-day instrument sensitivity drift. On two days, an identical GC-MS equipped with purge and trap facility was used to analyse surface seawater for dissolved halocarbon concentrations. Both systems and the measurements are described in further detail in Jones et al. (2009) and the measurements are summarised in Sect. 6.3.

\subsubsection{Nitrogen oxides and ozone}

$\mathrm{NO}_{\mathrm{x}}$ measurements were made by chemiluminescence using an Ecophysics CLD 780 TR nitric oxide analyser, with an Ecophysics PLC $762 \mathrm{NO}_{2}$ photolytic converter connected to a second analyser allow conversion of $\mathrm{NO}_{2}$ to NO. The reaction chambers in the $\mathrm{NO}$ analysers are held at constant temperature and pressure $\left(30^{\circ} \mathrm{C}\right.$ and $\left.10 \mathrm{mbar}\right)$, with the low internal pressure and high sample flow rate $(31 / \mathrm{min})$ allowing fast response to changes in the sample concentrations. Both analysers contain two chambers to allow interferences in the NO signal to be measured continuously. During measurements, $\mathrm{O}_{3}$ is added to the main reaction chamber where the resultant chemiluminescence from the rapid reaction of $\mathrm{NO}+\mathrm{O}_{3}$ is observed by a head on photomultiplier tube (PMT). A pre-chamber system, in which $\mathrm{O}_{3}$ is added upstream of the main reactor, is employed in order to correct for any chemical interferences and the PMT dark current. Since most interference reactions are slower than the $\mathrm{NO}+\mathrm{O}_{3}$ reaction, the PMT signal measured with $\mathrm{O}_{3}$ added in the pre-chamber is assumed to be the sum of the interferences and PMT dark current and therefore gives an instrument zero. The zero signal can then be subtracted from the main chamber signal giving a resultant signal that is assumed to be the result of the NO chemiluminescence only. The PMT is cooled to around $-15{ }^{\circ} \mathrm{C}$ in order to minimize the background counts, which is typically of the order of $1000 \mathrm{~s}^{-1}$. Air was sampled from an inlet on the mast of the CMAXDOAS instrument at the height of the LIF instrument nozzle ( $3.5 \mathrm{~m}$ above ground level) through quarter-inch PFA tubing. Air was continuously sampled (1 min averages) except during calibrations and when running zeros. The analysers were 
calibrated using a cylinder of $450 \mathrm{ppbv}$ NO in nitrogen, diluted to $4 \mathrm{ppb}$ in air by an Ecophysics PAG003 pure air generator and an Environics calibration gas blender S6100. The photolytic converter efficiency is also determined using gas phase titration of $\mathrm{NO}$ to $\mathrm{NO}_{2}$ by $\mathrm{O}_{3}$ as part of the calibration. Zero air was run through the system on several occasions to allow more accurate determination of the systematic artefact and detection limit. The $1 \sigma$ limit of detection for the $1 \mathrm{~min}$ frequency data was approximately $10 \mathrm{pptv}$ for $\mathrm{NO}$ and 15 pptv for $\mathrm{NO}_{2} . \mathrm{O}_{3}$ concentrations were measured using a UV absorption ozone analyser (2B Technologies Inc.). with a detection limit of $1.5 \mathrm{ppbv}$. The $\mathrm{NO}, \mathrm{NO}_{2}$ and $\mathrm{O}_{3}$ data were internally averaged to one minute frequency and are presented and discussed in Sect. 6.1.

In addition to the measurements of gaseous species concentrations, prototype systems for the determination of fluxes of halocarbons and molecular iodine by Relaxed Eddy Accumulation (REA) were deployed from the flux mast described in Sect. 4.4. The results of the measurements are the subject of ongoing analysis and will not be discussed further here. The halocarbon REA technique has undergone further development and has been reported in Hornsby et al. (2009).

\subsection{Radiometry}

A spectral radiometer (Edwards and Monks, 2003) was deployed from a mast on the roof of the same container as the BBCRDS, BBCEAS, max-DOAS and $\mathrm{NO}_{\mathrm{x}}$ chemiluminescence instruments. The radiometer provided continuous measurements of the solar actinic flux as a function of wavelength through an upward pointing $2 \pi$-sr hemisphere (wavelength range $280-700 \mathrm{~nm}$; spectral resolution $1 \mathrm{~nm}$ ). The flux data were averaged to $1 \mathrm{~min}$ integration times and then combined with molecular absorption cross sections and quantum yields to calculate photolysis frequencies for any photolabile species of interest, or summed in wavelength to provide the total actinic flux over the radiometer's bandwidth. Photolysis rates calculated from the spectral radiometry measurements are summarised in Sect. 6.2.

\subsection{Particle measurement techniques}

In addition to being used to derive particle fluxes (see Sect. 4.4.2), condensation particle counters (CPCs) were used to directly provide continuous number concentration time series of particles with diameters $D_{p}>3 \mathrm{~nm}$ and $D_{p}>$ $10 \mathrm{~nm}$ from the flux boom at the jetty, allowing derivation of the instantaneous concentration of number of particles with $10 \mathrm{~nm}>D_{p}>3 \mathrm{~nm}$. Background count levels are typically 0.0001 particles $\mathrm{cm}^{-3}$ with an absolute accuracy of $\pm 10 \%$ if properly maintained. CPCs measure total particle concentrations with sizes greater than a specific value determined by the instrument geometry and operating characteristics. The UCPC 3025AS has a 50\% detection efficiency for particles at $3 \mathrm{~nm}$ diameter, rising to $90 \%$ detection for $5 \mathrm{~nm}$ diameter par- ticles. The UCPC 3776 detects particles down to $2.5 \mathrm{~nm}$ with a 50\% efficiency, with almost $100 \%$ efficiency for $3 \mathrm{~nm}$ particles. The CPC 3010 has a $50 \%$ efficiency for $10 \mathrm{~nm}$ particles. Since the lower size threshold is not a step function, small errors will arise in the concentrations of particles calculated by differencing simultaneously collected data with diameters defined by these thresholds. Nevertheless, these data are conventionally reported without the associated errors (since an inaccessible size distribution across the threshold would be needed for their calculation) and this convention is followed in Sect. 6.4. In addition, the aerosol particle number size distributions were measured using a combination of a Scanning Mobility Particle Sizer (SMPS, TSI Model 3080L) and an optical particle counter (OPC, GRIMM Model 1.108). These instruments were located in the most Northerly and Westerly of the mobile laboratories shown in the bottom-right panel of Fig. 1. The SMPS was operated using a "long" Differential Mobility Analyser (DMA) column (TSI model 3080L) to size particles in the range $10-505 \mathrm{~nm}$ (mobility diameter) for the first part of the experiment and with the "short" column (TSI 3080S) for the last period, measuring from $3 \mathrm{~nm}$ to $160 \mathrm{~nm}$ mobility diameter, sampling down a short stainless steel inlet line directly into the instrument. Scan times in all cases were $6 \mathrm{~min}$. The OPC was used to size particles in the range $0.3-20 \mu \mathrm{m}$ optical scattering diameter in 16 size channels.

\subsection{Micrometeorological techniques}

Direct ultrafine particle and ozone fluxes were measured by Eddy Covariance (EC) and were reported in Whitehead et al. (2009a)(and are more fully described in Whitehead et al., 2009b). An ultrasonic anemometer with a resolution of $\pm 0.01 \mathrm{~ms}^{-1}$ and a frequency response of $50 \mathrm{~Hz}$ was colocated with a Krypton UV absorption hygrometer to capture high frequency water vapour fluctuations and thereby determine latent heat fluxes. High frequency absolute temperature and humidity measurements were also made using a co-located capacitance sensor. All the instruments were mounted on a variable position boom protruding $5 \mathrm{~m}$ beyond the jetty edge. Care was taken to ensure that the presence of the jetty wall was not influencing the air flow at the sensor location. A full description of the quality assurance and analysis is provided in Whitehead et al. (2009b).

\subsubsection{Ozone fluxes}

The ozone flux measurements were provided by a GFAS model OS-G-2 fast response $(20 \mathrm{~Hz})$ ozone sensor (Güsten et al., 1992; Güsten and Heinrich, 1996), based on the chemiluminescent reaction of ozone on a pre-sensitised dyeimpregnated silica gel disk. Disks were replaced typically every 48-72 $\mathrm{h}$ depending on the ambient accumulated ozone concentration and water vapour. The instrument response time and detection limit of $50 \mathrm{pptv}$, make it suitable for 
eddy covariance flux measurements. Calibration against a slower response Thermo Electron Corporation Model 49 ozone analyser ( $\mathrm{DL} \pm 1 \mathrm{ppbv}$, response time $20 \mathrm{~s}$ ) was carried out on each 15 min ozone flux measurement. The instrument inlet was co-located with the ultrasonic anemometer.

\subsubsection{Ultrafine particle fluxes}

Ultrafine particle fluxes were measured using an EC system comprising two CPCs (TSI models CPC 3010AS and UCPC 3776, which was replaced by a UCPC 3025AS on 11 September) - see Sect. 4.3. Details describing the use of these and similar particle counters to measure particle fluxes over different surfaces can be found in Buzorius et al. (1998) (forest surfaces), Dorsey et al. (2002) and Mårtensson et al. (2006) (urban surfaces), and Nemitz et al. (2002) (grasslands) and a review of micrometeorological methodologies and analysis techniques suitable for particle flux estimation can be found in Pryor et al. (2008). The eddy flux systems provided measurements of $F_{D_{p}>3}$ (flux for particles with sizes $D_{p}>3 \mathrm{~nm}$ ) and $F_{D_{p}>10}$, (flux for particles with sizes $\left.D_{p}>10 \mathrm{~nm}\right)$. The difference between these, $\Delta F=$ $F_{D_{p}>3}-F_{D_{p}>10}$, was used to provide a crude measure of the net particle formation flux; though strictly, the magnitude of this flux will be affected by the nature of the distribution between the instrument thresholds.

\section{Airmass classification, meteorological and tidal conditions}

Local wind direction and airmass history were highly variable throughout the RHaMBLe experiment. Figure 2 shows example calculated back trajectories based on ECMWF wind fields for selected days throughout the project. The following gives a brief summary of the prevailing meteorological conditions determining the airmass characteristics and the chemical context for the interpretation of the RHaMBLe coastal experiment.

From 7 to 9 September, air originated from the North Sea and UK and descended over France, arriving at the site in an Easterly direction. Levels of nitrogen oxides $\left(\mathrm{NO}_{\mathrm{x}}\right)$ were generally less than 5 ppbv.

From 10 to 13 September, the air was from the vicinity of the Azores and arrived at the site from a Southerly direction (over Brittany and the built up areas surrounding Roscoff) with afternoon sea breezes. Mixing ratios of $\mathrm{NO}_{\mathrm{x}}$ were quite elevated and representative of semi-polluted continental regions at between 10 and $30 \mathrm{ppbv}$.

Between 14 and 16 September, air arrived from the North Atlantic in a Northerly direction at the site, passing over Île de Batz. $\mathrm{NO}_{\mathrm{x}}$ loading indicated relatively unpolluted air at $\sim 3$ ppbv, but mostly significantly above clean marine levels (see Lee et al., 2010). On the night of 15 to 16 September, $\mathrm{NO}$ was very low (less than 5 unitpptv) but $\left[\mathrm{NO}_{2}\right]$ was greater than $1 \mathrm{ppbv}$. Such a ratio would be consistent with an injection of UK pollution.

Air that had come from the North Atlantic arrived at Roscoff from the West (along and over the coast) between 17 and 18 September. $\mathrm{NO}_{\mathrm{x}}$ was less than 2 ppbv (during the day) but with a "Rush hour" pollution peak on 18 September.

On 19 through to 24 September, North Atlantic air passed over the Bay of Biscay and the south coast of Brittany before arriving at Roscoff from the South. $\mathrm{NO}_{\mathrm{x}}$ was around 3 to 5 ppbv, 30 to $50 \%$ of it as NO. There was evidence of $\mathrm{O}_{3}$ production with levels reaching $50 \mathrm{ppbv}$.

On 25 September, air that had been continuously in the boundary layer for some time over the North Atlantic, arriving in a Westerly at the site (along the coast). Though relatively unpolluted $\left(\mathrm{NO}_{\mathrm{x}}\right.$ less than $\left.1 \mathrm{ppbv}\right)$ there was still more than 50 pptv NO at night. Between 26 and 27 September, North Atlantic air arriving at the site from a Southerly direction over the town of Roscoff.

Figure 3 shows the frequency of local wind speed and direction throughout the RHaMBLe experiment from one minute averaged data from the ultrasonic anemometer located on the jetty (see Sect. 4.4).

The period chosen for the RHaMBLe experiment coincided with the month spanning the deepest spring tides. With a tidal amplitude of $9.6 \mathrm{~m}$, the one month experiment provided the opportunity to experience a wide variety of intertidal ranges under both daylight and night-time conditions. Tidal height variation through the RHaMBLe experiment is shown plotted with the various gaseous concentration measurements in Figs. 5, 7, 8, 10, 11, and 12 and is used in the $\mathrm{I}_{2}$ emission modelling reported by Leigh et al. (2009), see Sect. 7 (footprints, tidal exposure convolved to bathymetry and macroalgal emissions illustrated in Fig. 14).

\section{Results}

\subsection{Chemical context of the experiment; $\mathrm{NO}_{\mathrm{x}}$ as an indicator of pollution}

Figure 4 shows mixing ratios of $\mathrm{NO}_{\mathrm{x}}$ taken from the jetty site during the Roscoff campaign. The sampling inlet for $\mathrm{NO}$ and $\mathrm{NO}_{2}$ was on the same mast as the CMAX-DOAS instrument and, at $3.5 \mathrm{~m}$, at the same height as the IO measurement by LIF. This location ensured that when the wind was from 90 to $270^{\circ}$ it was crossing the town of Roscoff before being sampled and from all other directions, the air had not passed over the town but came directly from the sea. The wind roses show that the largest NO levels are seen when the air is from a SE direction, with $\sim 2$ ppbv observed. The high NO levels indicate that the sampling site is very close to emissions in this wind direction, as may be expected by the close proximity of the town. Levels of NO are much lower $(<1 \mathrm{ppbv})$ when the air arrives from the more lightly populated SW direction, locally crossing an extensive bay 

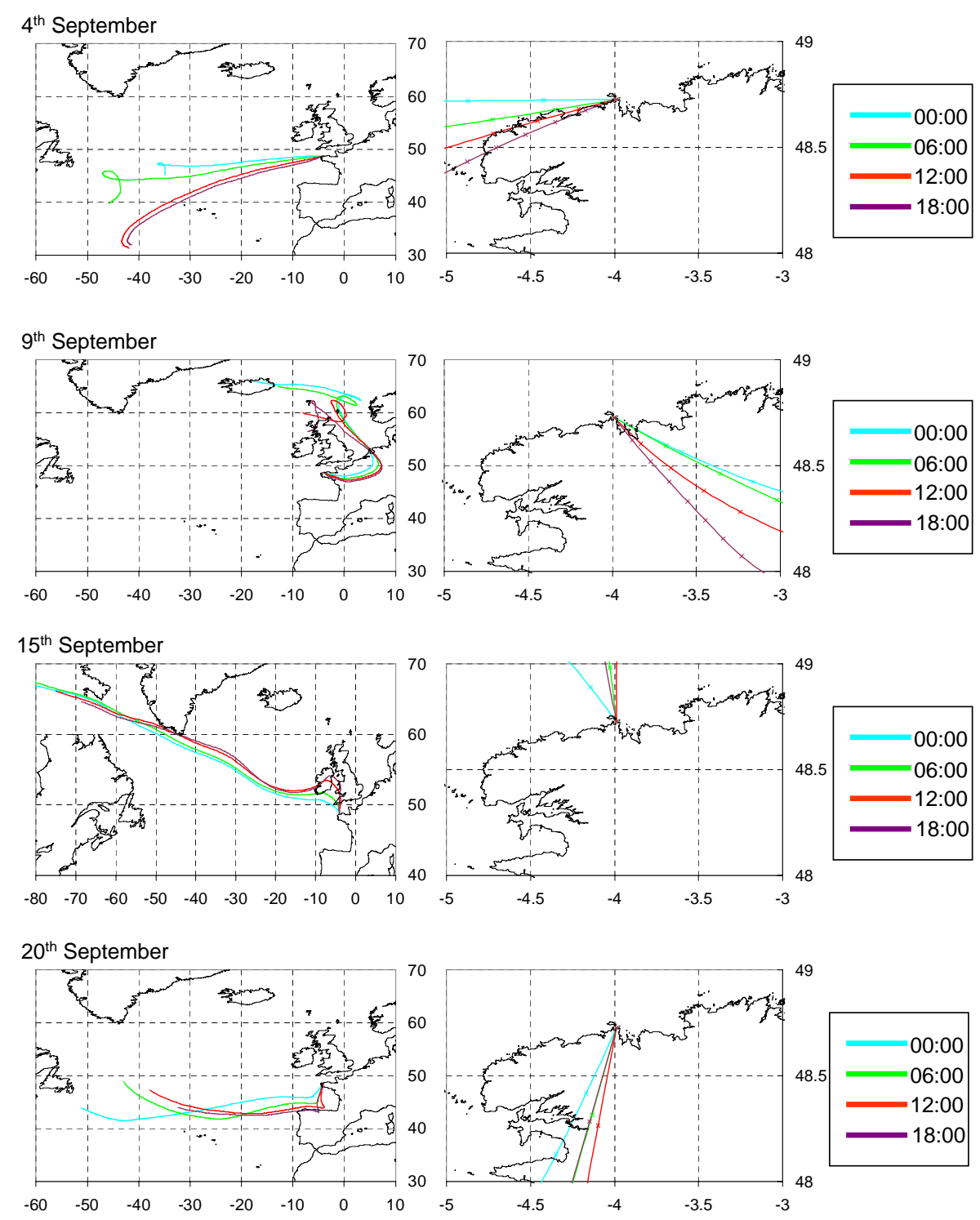

Fig. 2. Example 5-day back trajectories calculated using the ECMWF web trajectory service at the BADC. On 4 September (top panel), air was relatively clean marine, but from early morning passed along extensive stretches of the North Brittany coastline before arriving at the measurement site from a Westerly direction. On 9 September (2nd panel), air had been over mainland France for a significant time since arriving across the North Sea and arrived at the site from a South Easterly direction. On 15 September (3rd panel), air arrived at the site from a Northerly direction having crossed the Channel from the UK. As the day progressed, the air had progressively spent longer over the UK. On 20 September (4th panel), air arrived at the site from the SSW having crossed the coast of South Brittany from the Bay of Biscay, originating from the Iberian peninsula.

immediately to the SW of the sampling site. Despite this, $\mathrm{NO}_{2}$ levels are $\sim 2 \mathrm{ppbv}$ in the $\mathrm{SW}$ direction, similar to those from the SE, suggesting more processed, but still polluted, air. In the NE direction, when the NO levels are 0.5 to 1.0 ppbv with $\mathrm{NO}_{2} 1$ to 2 ppbv, the air has not passed over any land from this direction. However, there is a busy port to the NE of the measurement site and this could account for the relatively high $\mathrm{NO}_{\mathrm{x}}$ levels observed in this direction. From the $\mathrm{NW}, \mathrm{NO}_{\mathrm{x}}$ levels are significantly lower $(\mathrm{NO}<0.5 \mathrm{ppbv}$,
$\mathrm{NO}_{2}<1$ ppbv) though still elevated above Northern Hemisphere marine background. Air from this sector may have passed over Île de Batz, an inhabited island $\sim 1 \mathrm{~km}$ NW of the measurement site; in any case, the $\mathrm{NO}_{\mathrm{x}}$ levels are characteristic of regional background pollution. $\mathrm{NO}$ and $\mathrm{NO}_{2}$ levels typical of clean marine background air $(<0.1 \mathrm{ppbv}$ and $<0.2$ ppbv respectively) were sampled from local wind directions between $270^{\circ}$ and $300^{\circ}$ likely not to have passed over the Île de Batz, but directly from the English Channel. The 

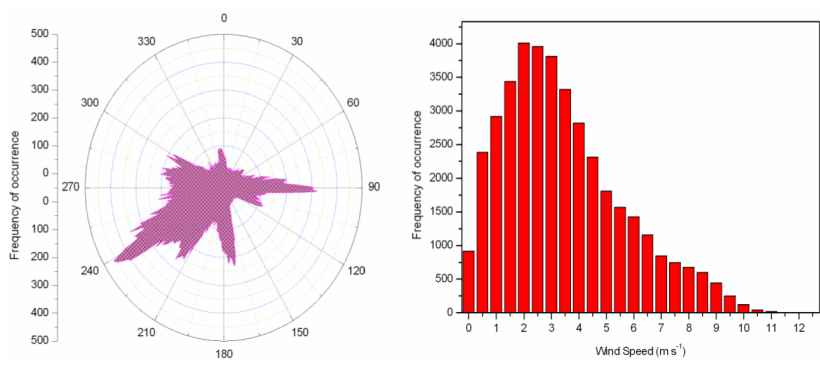

Fig. 3. Frequency plot of (a) wind direction $\left(1^{\circ}\right.$ binned $)$ and (b) wind speed $\left(0.5 \mathrm{~ms}^{-1}\right.$ binned) throughout the experiment. It can be seen that the air most frequently arrived at the measurement site from the lightly inhabited SW area, locally tracking across an extensive intertidal bay.
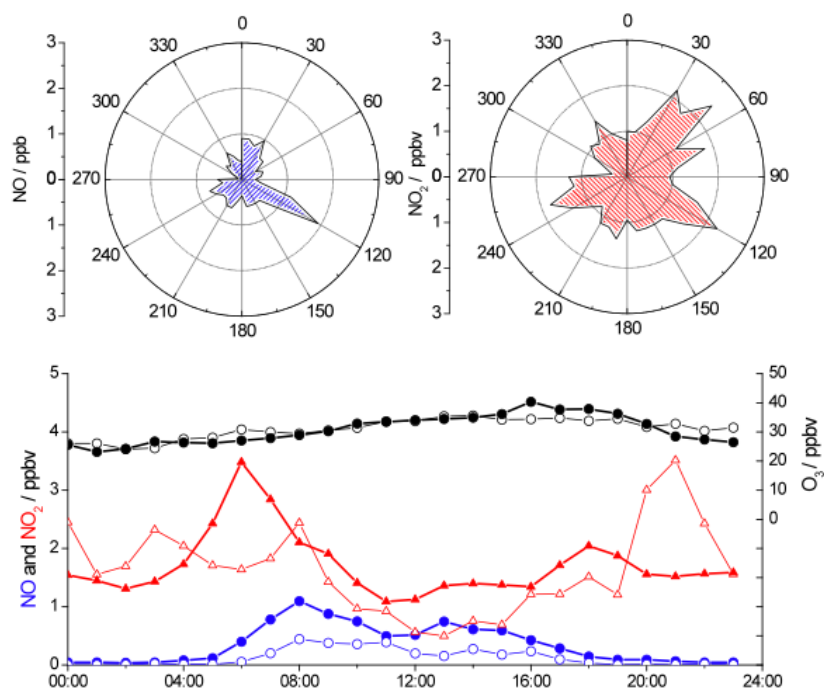

Fig. 4. $\mathrm{NO}_{\mathrm{x}}$ and $\mathrm{O}_{3}$ throughout the RHaMBLe project in Roscoff. The wind roses show the highest NO is seen in air from a SE direction, indicating very local emissions from Roscoff town. Lower $\mathrm{NO}$ was measured from the $\mathrm{SW}$. $\mathrm{NO}_{2}$ levels are comparable from the SW and SE, suggesting more processed, but still polluted, air. Roscoff port is likely to contribute to relatively high $\mathrm{NO}_{\mathrm{x}}$ levels observed in air from the NE of the measurement site. From the NW, $\mathrm{NO}_{\mathrm{X}}$ is significantly lower, though still characteristic of regional background pollution. $\mathrm{NO}$ and $\mathrm{NO}_{2}$ levels typical of clean marine background air were sampled from wind directions between 270 and $300^{\circ}$. The lower panel shows median diurnal cycles for NO (blue), $\mathrm{NO}_{2}$ (red) and $\mathrm{O}_{3}$ (black) for air that had broadly passed over the land from a Southerly direction (filled symbols) and the sea from a Northerly direction (open symbols). Daytime NO levels are higher in the Southerly air compared to the Northerly air. The Southerly air shows reasonably constant levels of $\mathrm{NO}_{2}$ throughout the day, with a peak in early morning $(\sim 06: 00)$. In Northerly air, $\mathrm{NO}_{2}$ peaks at at night, with a minimum at midday. The diurnal cycles of $\mathrm{O}_{3}$ in the two conditions are similar exhibiting apparent photochemical production with a peak at $\sim 16: 00$. lower panel in Fig. 4 shows median diurnal cycles for NO, $\mathrm{NO}_{2}$ and $\mathrm{O}_{3}$ for air that had broadly passed over the land (from a Southerly direction) and the sea (from a Northerly direction). Both conditions show similar trends in NO and $\mathrm{NO}_{2}$, with very little $\mathrm{NO}$ at night, a peak in the morning at sunrise (coincident with rush hour), followed by reasonably constant levels throughout the day. There is a clear difference between the two conditions, with the early morning NO peak being $1.1 \mathrm{ppbv}$ in the Southerly air and $0.4 \mathrm{ppbv}$ in the Northerly air. The daytime NO levels are also higher in the Southerly air $(\sim 0.5 \mathrm{ppbv})$ compared to the Northerly air $(\sim 0.2 \mathrm{ppbv})$. The Southerly air shows reasonably constant levels of $\sim 1.5 \mathrm{ppbv} \mathrm{NO}_{2}$ throughout the day, with a peak of up to 3 ppbv in early morning ( $\sim 06: 00)$. In the Northerly air, $\mathrm{NO}_{2}$ peaks at $\sim 2.2 \mathrm{ppbv}$ at night, with a minimum of $\sim 0.4 \mathrm{ppbv}$ at midday. The diurnal cycle of $\mathrm{O}_{3}$ in the two conditions is similar, both being $\sim 25 \mathrm{ppbv}$ at night and exhibiting apparent photochemical production with a peak at $\sim 16: 00$. The peak is higher in the Southerly air compared to the Northerly ( $\sim 40 \mathrm{ppbv}$ compared to $\sim 34 \mathrm{ppbv})$, demonstrating the extra photochemical production of $\mathrm{O}_{3}$ resulting from the extra $\mathrm{NO}_{\mathrm{x}}$ in the Southerly, more polluted air.

Figure 5 shows time series of all oxidised nitrogen species concentrations measured by all instruments throughout the experiment. It is clear that there the measurement site was exposed to significant and continuous anthropogenic pollution throughout the RHaMBLe experiment. Both NO and $\mathrm{NO}_{2}$ concentrations are highly variable and are quite obviously considerably larger than those typical of remote coastal regions such as at Mace Head during NAMBLEX. Although not the principal target of the BBCRDS instrument during this deployment, co-retrieval of $\mathrm{NO}_{2}$ concentrations served as an important quality assurance parameter with which to monitor the BBCRDS instrument's performance when measuring $\mathrm{I}_{2}$. Throughout the experiment, the $\mathrm{NO}_{2}$ concentrations measured by BBCRDS were in excellent quantitative agreement with $\mathrm{NO}_{2}$ measurements made by the chemiluminescence instrument. The insert in Fig. 5 shows an example of the close agreement between the two BBCRDS and chemiluminescence instruments when measuring $\mathrm{NO}_{2}$ on 14-15 September (the gradient of a correlation plot of these data is $0.98 \pm 0.03$ ).

The BBCEAS instrument detected substantial amounts of $\mathrm{NO}_{3}+\mathrm{N}_{2} \mathrm{O}_{5}$ on two nights (40 pptv max on 14/15 September and $80 \mathrm{pptv}$ max on 15/16 September) and smaller amounts on a third night (5 pptv on 20/21 September). Otherwise the $\mathrm{NO}_{3}+\mathrm{N}_{2} \mathrm{O}_{5}$ amounts were at or below the instrument's detection limit of $1.5 \mathrm{pptv}$ (10 s integration time) - see third panel in Fig. 5. On the two nights when the largest $\mathrm{NO}_{3}+\mathrm{N}_{2} \mathrm{O}_{5}$ amounts were detected, the site was receiving very clean air from the north $([\mathrm{NO}]<10 \mathrm{pptv})$ and the $\mathrm{NO}_{3}+\mathrm{N}_{2} \mathrm{O}_{5}$ concentrations closely tracked the $\mathrm{NO}_{2}$ concentrations measured by the chemiluminescence instrument $\left(\left[\mathrm{NO}_{2}\right]\right.$ ranged between 2 and $\left.10 \mathrm{ppbv}\right)$. A simple kinetic model suggested that $70-90 \%$ of $\mathrm{NO}_{3}+\mathrm{N}_{2} \mathrm{O}_{5}$ measured on 


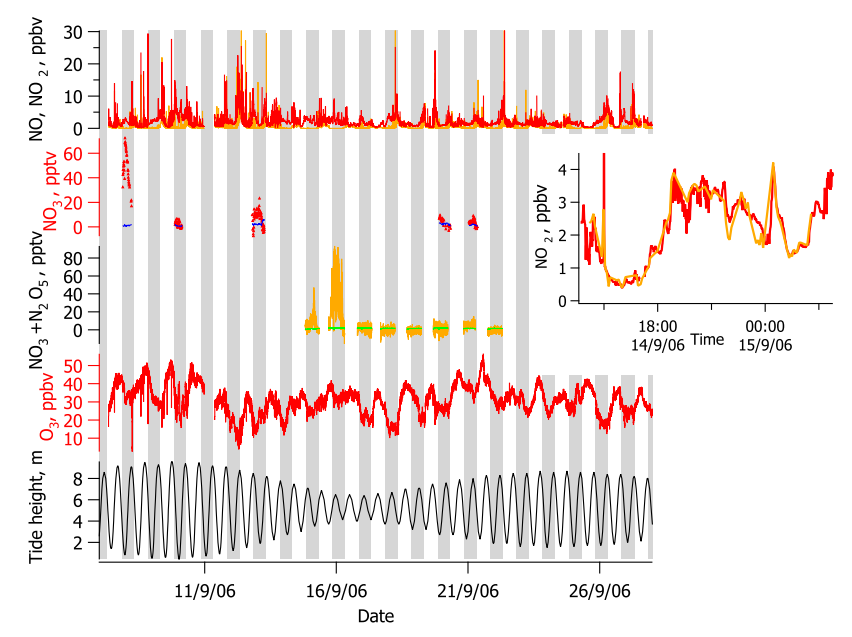

Fig. 5. Time series of all oxidised nitrogen species measured during the RHaMBLe experiment. The top panel shows traces of $\mathrm{NO}_{2}$ in red and NO in orange, measured by the in situ chemiluminenscence instrument. The second panel shows the path-integrated DOAS $\mathrm{NO}_{3}$ mixing ratios in red with the associated detection limits whilst the third panel shows the BBCEAS measured in situ mixing ratios of the $\Sigma\left(\mathrm{NO}_{3}+\mathrm{N}_{2} \mathrm{O}_{5}\right)$. There were no periods of simultaneous observations of elevated concentrations of LP-DOAS $\mathrm{NO}_{3}$ and BBCEAS $\Sigma\left(\mathrm{NO}_{3}+\mathrm{N}_{2} \mathrm{O}_{5}\right)$. The fourth panel shows the time series of $\mathrm{O}_{3}$ mixing ratios and the fifth the tidal height for reference. Day and night is indicated by the grey and white striping. The insert shows the good agreement between the chemiluminescence and BBCRDS measured $\mathrm{NO}_{2}$ mixing ratios on the 14 and 15 September.

these nights was present as $\mathrm{N}_{2} \mathrm{O}_{5}$, assuming rapid equilibration between $\mathrm{NO}_{3}$ and $\mathrm{N}_{2} \mathrm{O}_{5}$. The wind direction was typically from the south (i.e. from over Roscoff town) for the other the nights when $\mathrm{NO}_{3}+\mathrm{N}_{2} \mathrm{O}_{5}$ was not observed and night-time NO concentrations remained around 50-100 pptv (with considerably larger transient spikes). This was seemingly sufficient $\mathrm{NO}$ for the rapid $\mathrm{NO}+\mathrm{NO}_{3} \rightarrow 2 \mathrm{NO}_{2}$ reaction suppress all $\mathrm{NO}_{3}+\mathrm{N}_{2} \mathrm{O}_{5}$ at the site.

LP-DOAS measurements of $\mathrm{NO}_{3}$ are reported in Mahajan et al. (2009a) and mixing ratios were retrieved on nine nights with concentrations ranging from $<2 \mathrm{pptv}$ to $72.1 \pm 1.8 \mathrm{pptv}$ (on 7-8 September).

\subsection{Radiometry}

The main panel of Fig. 6 shows the photolysis frequencies of $\mathrm{I}_{2}$ convolved from the measured spectral intensities. It can be seen that the diurnal variation in solar intensity was comparable in magnitude throughout the experiment, with two relatively cloudy days on 2 and 6 September. The smaller panels of Fig. 6 each show the diurnal profiles of the photolysis rates for individual gaseous species on 10 September grouped according to their photolability (from shortest- to longest-lived, top left, top right, bottom left, bottom right). Typical midday clearsky photolysis frequencies were, in units of $\mathrm{s}^{-1}$,
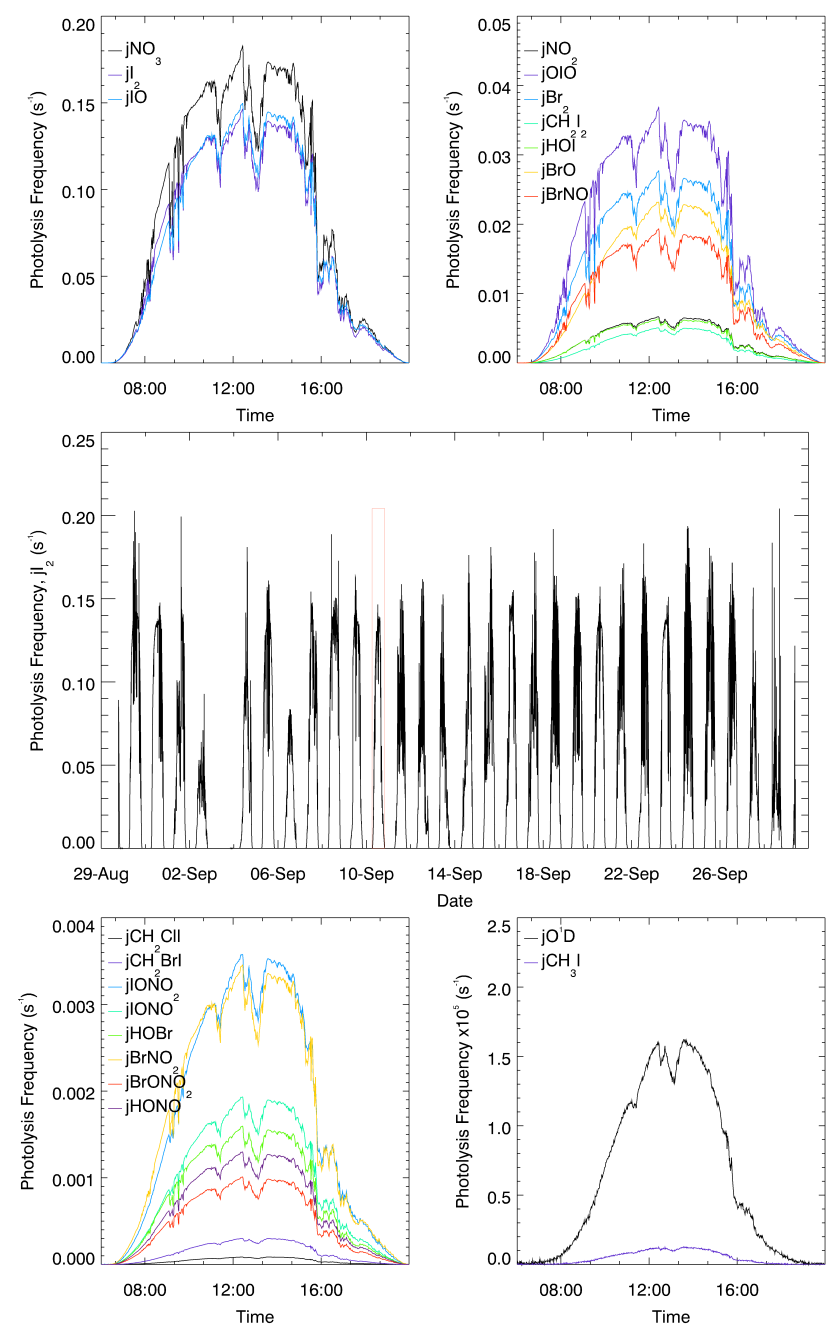

Fig. 6. Photolysis rates calculated from spectrally-resolved irradiance radiometer measurements. Central panel is full time series of $\mathrm{j}_{2}$. Insets, clockwise from top left, photolysis rates of important gaseous components grouped by their photolysis rates, highest to lowest.

$\mathrm{j}_{\mathrm{NO}_{3}}=0.18$

$\mathrm{j} \mathrm{IO}=0.147$,

$\mathrm{j}_{\mathrm{I}_{2}}=0.143$,

jOIO $=3.7 \times 10^{-2}$,

$\mathrm{j}_{\mathrm{Br}_{2}}=2.73 \times 10^{-2}$,

$\mathrm{j}_{\mathrm{BrO}}=2.3 \times 10^{-2}$,

$\mathrm{j}_{\mathrm{BrNO}}=1.88 \times 10^{-2}$,

$\mathrm{j}_{\mathrm{NO}_{2}}=6.5 \times 10^{-3}$,

$\mathrm{j}_{\mathrm{HOI}}=6.2 \times 10^{-3}$,

$\mathrm{j}_{\mathrm{CH}_{2} \mathrm{I}_{2}}=4.7 \times 10^{-3}$,

$\mathrm{j}_{\mathrm{INNO}_{2}}=3.6 \times 10^{-3}$,

$\mathrm{j}_{\mathrm{BrNO}_{2}}=3.45 \times 10^{-3}$,

$\mathrm{j}_{\mathrm{IONO}}=1.95 \times 10^{-3}$,

$\mathrm{j}_{\mathrm{HOBr}}=1.6 \times 10^{-3}$,

$\mathrm{j}_{\mathrm{BrONO}_{2}}=1.0 \times 10^{-3}$, 

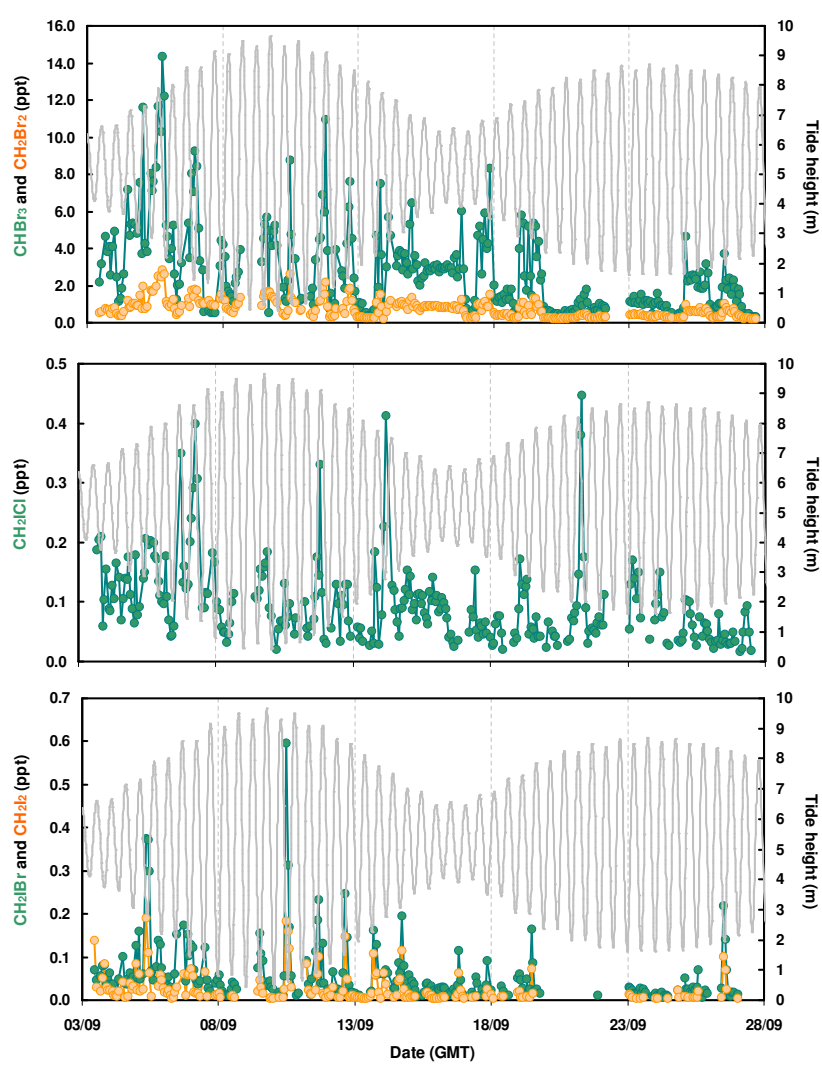

Fig. 7. Time series of a selection of GC/MS-measured short-lived halocarbons $\left(\mathrm{CH}_{2} \mathrm{Br}_{2}, \mathrm{CHBr}_{3}, \mathrm{CH}_{2} \mathrm{ICl}, \mathrm{CH}_{2} \mathrm{IBr}\right.$ and $\left.\mathrm{CH}_{2} \mathrm{I}_{2}\right)$ with superimposed tidal height.

$\mathrm{j}_{\mathrm{CH}_{2} \mathrm{BrI}}=2.7 \times 10^{-4}$,

$\mathrm{j}_{\mathrm{CH}_{2} \mathrm{CII}}=1.0 \times 10^{-4}$,

$\mathrm{j}_{\mathrm{O}_{3} \rightarrow \mathrm{O}\left({ }^{1} \mathrm{D}\right)}=1.63 \times 10^{-5}$ and

$\mathrm{j}_{\mathrm{CH}_{3} \mathrm{I}}=1.5 \times 10^{-6}$.

The deviations from the broadly Gaussian profiles result from sporadic cloud cover. The spectral radiometer operated from late afternoon on 29 August 2006 until the morning of 29 September 2006 with missing data on 3 September.

\subsection{Gaseous halogen species concentrations}

\subsubsection{Halocarbon observations}

Figure 7 shows the time series of a selection of short-lived halocarbons measured throughout the experiment. These are presented in detail by Jones et al. (2009). Very much lower iodocarbon concentrations were observed at Roscoff than further along the Breton coast at Lilia (Peters et al., 2005), and were more comparable with the those observed at Mace Head (Carpenter et al., 1999; Carpenter, 2003). The mean mixing ratios of the shortest lived halocarbons, the dihalomethanes $\mathrm{CH}_{2} \mathrm{ICl}, \mathrm{CH}_{2} \mathrm{IBr}$ and $\mathrm{CH}_{2} \mathrm{I}_{2}$, in the ambient air at Roscoff were $0.1,0.06$ and 0.03 pptv respectively, while the bromocarbons $\mathrm{CH}_{2} \mathrm{Br}_{2}$ and $\mathrm{CHBr}_{3}$ were observed with mean mixing ratios of 0.75 and 2.73 pptv respectively.

Concentrations of the shortest-lived dihalomethanes, $\mathrm{CH}_{2} \mathrm{IBr}$ and $\mathrm{CH}_{2} \mathrm{I}_{2}$, showed a statistically-significant tidal dependence (higher at low tide). Jones et al. (2009) also report a limited number of measurements of halocarbons in surface seawater, estimating sea-air fluxes based on simultaneous water and air concentrations. Both $\mathrm{CH}_{2} \mathrm{Br}_{2}$ and $\mathrm{CHBr}_{3}$ were strongly correlated in both air and seawater, with $\mathrm{CH}_{2} \mathrm{Br}_{2} / \mathrm{CHBr}_{3}$ ratios of 0.19 in air and 0.06 in water.

\subsubsection{Inorganic iodine observations}

A summary of all inorganic iodine concentration measurements made throughout the experiment is presented in Fig. 8.

LP-DOAS retrievals of $\mathrm{I}_{2}$, IO or OIO were obtained on 22, 17 and 22 days respectively throughout the experiment and the measurements are reported in Mahajan et al. (2009a). Since the LP DOAS technique requires alternation between spectral regions to detect $\mathrm{IO}$ and $\mathrm{I}_{2} / \mathrm{OIO}$, simultaneous measurements of all these species was not possible. IO and $\mathrm{I}_{2}$ concentrations correlate strongly with tide. The highest mixing ratio of IO (10.1 $\pm 0.7 \mathrm{pptv})$ was observed on 9 September 2006, when the spring tidal variation was $9.6 \mathrm{~m}$. Despite its short photolysis lifetime, $\mathrm{I}_{2}$ was measured whenever the DOAS was tuned to the appropriate spectral range during the daytime, indicating that the DOAS light beam passed close by an extremely strong primary source or very efficient recycling mechanism. However, even when $\mathrm{I}_{2}$ was present at the highest path-integrated mixing ratios (e.g. up to $25.9 \pm 3.1 \mathrm{pptv}$ on 19 September 2006), OIO was not observed above the detection limit ( $\sim 4 \mathrm{pptv})$ during any of the 6 daytime measurement periods. $\mathrm{I}_{2}$, IO and OIO were all observed at night. When detected at night, $\mathrm{I}_{2}$ and IO were again shown to exhibit a tidal relationship and, in contrast to the daytime, OIO was also observed. Maximum night-time mixing ratios of $\mathrm{IO}, \mathrm{I}_{2}$ and $\mathrm{OIO}$ were $3.0 \pm 0.9$, $52.3 \pm 4.2$ and $8.7 \pm 2.3 \mathrm{pptv}$ respectively. IO was detected on two out of eight nights, whereas OIO and $\mathrm{I}_{2}$ were detected on seven out of thirteen nights. During daytime low tide, peak iodine species mixing ratios were variable, ranging from 24.3-32.8 pptv for $\mathrm{I}_{2}$ with an average of $28.7 \mathrm{pptv}$ and $4.8-10.1 \mathrm{pptv}$ for IO with an average of $7.5 \mathrm{pptv}$. Over the entire time series, the daytime $\mathrm{I}_{2} / \mathrm{IO}$ ratio ranged from 2.4 to 5.8 , with an average of 3.8 .

FAGE LIF measurements of IO during RHaMBLe have been reported briefly in Whalley et al. (2007) and are more extensively discussed in Furneaux et al. (2009). Measurements were made over a period of 20 days (7 to 28 September 2006). IO was measured above the instrument DL (0.4$4 \mathrm{pptv}$ for a $150 \mathrm{~s}$ integration period, see Sect. 4.1) on 14 days, of which a clear diurnal profile was observed on 11 days. The maximum daytime IO was $30.0 \pm 7.1 \mathrm{pptv}$ (10 s integration period). IO was below DL or scattered around zero on the remaining days. Night-time IO was detected on two 


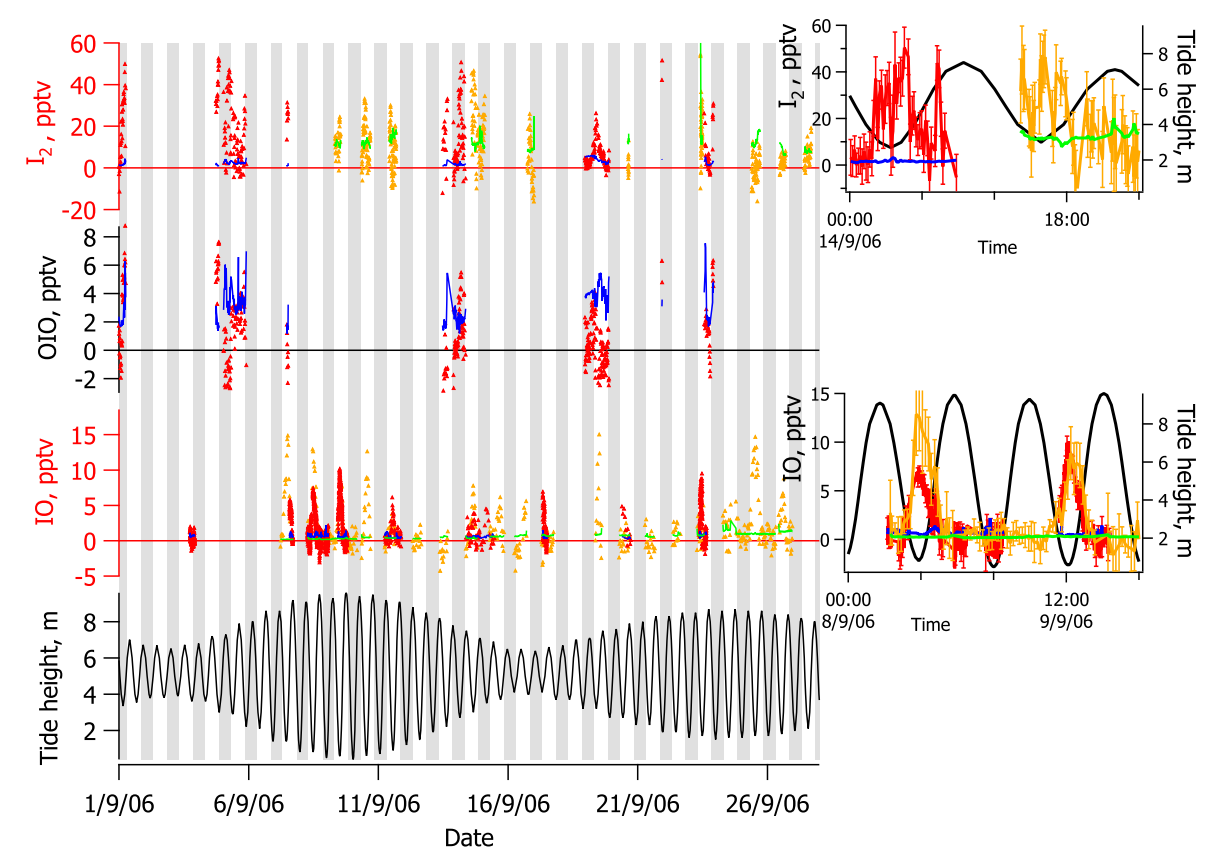

Fig. 8. Time series of inorganic gaseous iodine compounds measured throughout the RHaMBLe experiment. The red symbols are pathintegrated LP-DOAS measurements and the yellow triangles correspond to in situ $\mathrm{I}_{2}$ measurements by BBCRDS and IO measurements by FAGE LIF. The top-right insert shows long-path and in situ $\mathrm{I}_{2}$ measurements on subsequent early morning and late afternoon low tidal periods respectively, with their associated errors. The bottom-right insert shows contemporaneous long-path and in situ IO measurements on two subsequent daytime low tidal periods, with their associated errors.

of four measurement nights, at mixing ratios of $1.1-2.0 \mathrm{pptv}$ (60 min average). There were three periods during the campaign when IO was not detected which Furneaux et al. (2009) explained in terms of the combination of a lack of macroalgae exposure (neap tides) or meteorological conditions. This is discussed further in Sect. 7.

BBCRDS measurements of $I_{2}$ were made on 10 days between 9 and 27 September, and the time series of the $I_{2}$ concentrations is shown in the top panel of Fig. 8 . $\mathrm{I}_{2}$ was measured above the instrument's detection limit (10-15 pptv for a 5 minute integration time) on 4 days, all in the first half of the campaign. On all these day, $\mathrm{I}_{2}$ concentrations peaked around low tide, the highest daytime $\mathrm{I}_{2}$ concentration being 50 pptv around the early evening low tide on 14 September. No $I_{2}$ was subsequently observed above the detection limit overnight on 14/15 September, although there are hints of $\mathrm{I}_{2}$ returning towards the low tide just before dawn on the 15 September. A small amount of $I_{2}$ ( $\max \sim 25$ pptv) was observed for the low tide just after sunset on 16 September. No $I_{2}$ was observed at the site on the 25 and 26 September. (both midday low tides) when some of the largest IO concentrations of the entire campaign were detected by FAGE (20 and 12 pptv max, respectively) and when substantial numbers of small particles were also detected at the site. On these occasions, the air had clearly previously been in contact with some large $\mathrm{I}_{2}$ or iodocarbons emissions, but any $\mathrm{I}_{2}$ had been consumed before the air reached the in situ measurement site. Leigh et al. (2009) provide a more detailed discussion of the BBCRDS $I_{2}$ measurements and how individual days' data compare with results from a model of $I_{2}$ emissions and their transport to the measurement site.

The narrow-band CRDS measurements of IO as reported by Wada et al. (2007) are not shown on Fig. 8, but were broadly in agreement with the LIF measurements, in that they exhibited a clear tidal signal on the two measurement days available ( 8 and 25 September) at elevated mixing ratios, greater than those observed by the LP-DOAS.

It is evident from Fig. 8 that path-integrated and in situ measurements of iodine species exhibit significant differences in magnitude. In general, the $\left[\mathrm{I}_{2}\right]_{\mathrm{BBCRDS}}$ was comparable in magnitude to the $\left[\mathrm{I}_{2}\right]_{\mathrm{LP}-\mathrm{DOAS}}$, whereas the $[\mathrm{IO}]_{\mathrm{LIF}}$ (and [IO $]_{\text {CRDS }}$ when available) was generally elevated above

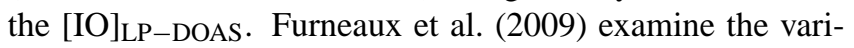
ability in $[\mathrm{IO}]_{\text {LIF }} /[\mathrm{IO}]_{\text {LP-DOAS }}$ confirming the non-uniform distribution of iodine species consistent with "hot-spot" particle precursors postulated by Saiz-Lopez et al. (2006) for the Mace Head experiments.

CMAX-DOAS retrieval of IO was performed on 17 days between 5 and 26 September and DSCDs are presented in Fig. 9. IO DSCDs were often detected above the average detection limit of approximately $3 \times 10^{13}$ molecule $^{-2}$ and showed a clear tidal signal in one or more of the viewing 

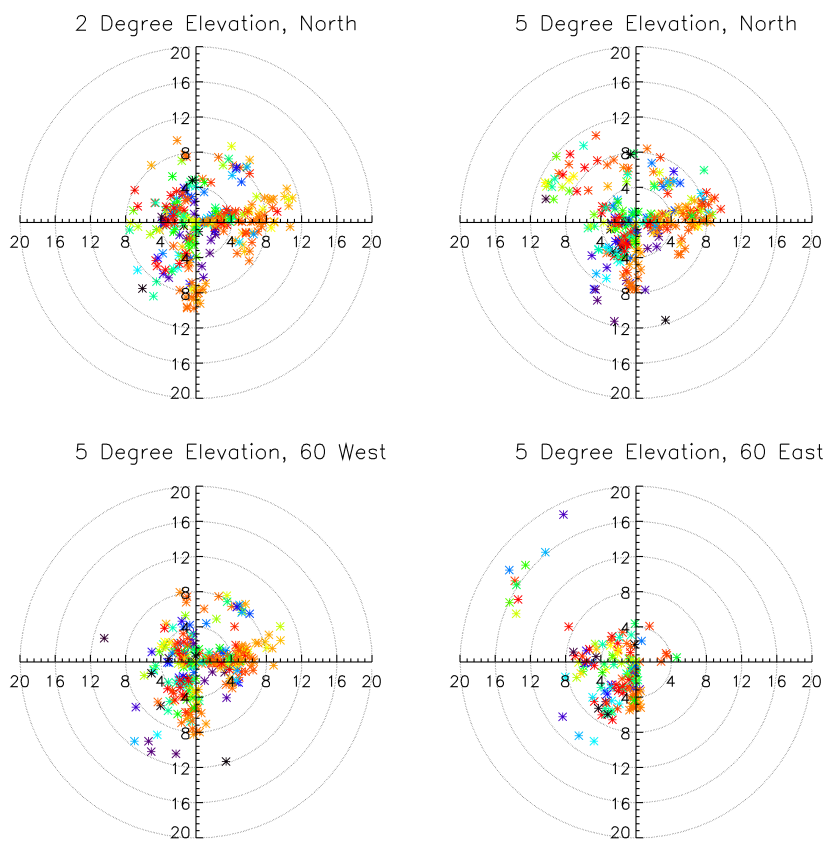

Fig. 9. Differential slant column densities as measured by the CMAX-DOAS instrument from 5 to 26 September from the four primary viewing geometries. The wind direction is indicated by the angle on the polar plot and the radial distance designates the

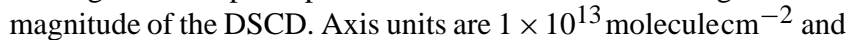
marker colours denote $\mathrm{I}_{2}$ photolysis frequency at the time of measurement, from blue (zero) to red $\left(0.25 \mathrm{~s}^{-1}\right)$.

angles on 10 days, with high IO DSCDs anti-correlated with tidal height. In the early part of the experiment, air masses arrived from an Easterly direction and corresponded with high IO DSCDs in the Northerly and Westerly views, most likely from emission sources on the East coast of Île de Batz. The $5^{\circ}$ Easterly viewing telescope was not installed until 13 September and missed a significant number of these air masses. During some days, the peaks in CMAX-DOAS measured IO DSCD occur at different times and with different magnitudes, depending on the viewing angle, supporting the contention that IO is inhomogeneously distributed (see Sect. 7.2).

\subsubsection{Bromine monoxide observations}

LP-DOAS retrieval of $\mathrm{BrO}$ was carried out on 16 days between 6 and 23 September and $\mathrm{BrO}$ was observed on 8 days. Assuming homogenous distribution along the DOAS light path, the concentrations varied from under the detection limit (2pptv) to a maximum of $7.5 \pm 1.0 \mathrm{pptv}$. The radical did not exhibit a clear diurnal profile which correlated either with the tidal cycle or the intensity of solar irradiance. At night, $\mathrm{BrO}$ was consistently below the DOAS detection limit as it was on a few days during daytime. The $\mathrm{BrO}$ measurements will not be discussed in any further detail here and are presented in Mahajan et al. (2009b).
CMAX-DOAS retrieval of $\mathrm{BrO}$ was performed on four days between 17 and 20 September 2006. BrO was observed above the detection limit on all four days. There was no clear dependence of BrO DSCDs on tide state with elevated levels observed in some viewing angles at low tide but also during periods of high tide when correlated with high irradiance.

\subsection{Particle measurements}

Very strong bursts of ultrafine particles $\left(10 \mathrm{~nm}>D_{p}>3 \mathrm{~nm}\right)$ lasting around five hours were observed on almost all days where there was a daytime low tide and the clear relationship is shown in the lower panel of Fig. 10. The upper panel shows the continuous time series of in situ LIF measurements, demonstrating the clear correspondence of the magnitudes of particle concentrations and IO mixing ratios. Furneaux et al. (2009) provides a detailed analysis of this relationship. The particle concentrations in the lower panel have been averaged to the $5 \mathrm{~min}$ integration time of the IO measurements, but even these averaged values reach $1.9 \times$ $10^{5} \mathrm{~cm}^{-3}$ during deep low tides. The mean particle number concentrations throughout the spring tide bursts between 7 and 11 September were as high as 95000 particles $\mathrm{cm}^{-3}$, reaching peaks of one minute averaged number concentrations of around $2.5 \times 10^{5}$ particles $\mathrm{cm}^{-3}$

On several of the days, most notably those with the deepest daytime low tides, particle growth to sizes of several tens of $\mathrm{nm}$ (in some cases to greater than $100 \mathrm{~nm}$ ) diameter may be inferred from the SMPS-measured size distributions. For example, the lower panel of Fig. 11 shows number concentration following particle production bursts on 8 and 9 September propagated continuously through to larger sizes and persisted at the measurement site into the afternoon of 10 September. The particles are formed as sub-detectable clusters, initially observed once they have reached $3 \mathrm{~nm}$ diameter (by the difference in CPC measurements, one minute average values shown in the upper panel), and it can be directly inferred from the size distributions shown in the lower panel that they grow to sizes of greater than $120 \mathrm{~nm}$ in a timescale of tens of hours. Particle growth rates may be estimated from the rate of change of the mode in the size distribution (e.g. Dal Maso et al., 2002). From the data in Fig. 11, an apparent growth rate of around $10-15 \mathrm{nmh}^{-1}$ can be estimated, decreasing with time and increasing size, as the plume is diluted. The lower size cut-off of the SMPS during these measurements was $10 \mathrm{~nm}$ and, from the decreasing growth rate with increasing size, it may be reasonably assumed that growth rates are likely to be higher at sizes below the SMPS lower threshold. By assuming the lag in particle burst onset times (i.e. number concentrations recorded by the two CPCs increase resulting from the nucleation event) is the time taken for particles to grow from $2.5 \mathrm{~nm}$ (UCPC 3776 , or $3 \mathrm{~nm}$ when the UCPC $3025 \mathrm{AS}$ was operating) to $10 \mathrm{~nm}$, the early stage growth rate was estimated in the range $17-150 \mathrm{nmh}^{-1}$. It must be noted that this assumes a step change in the response 


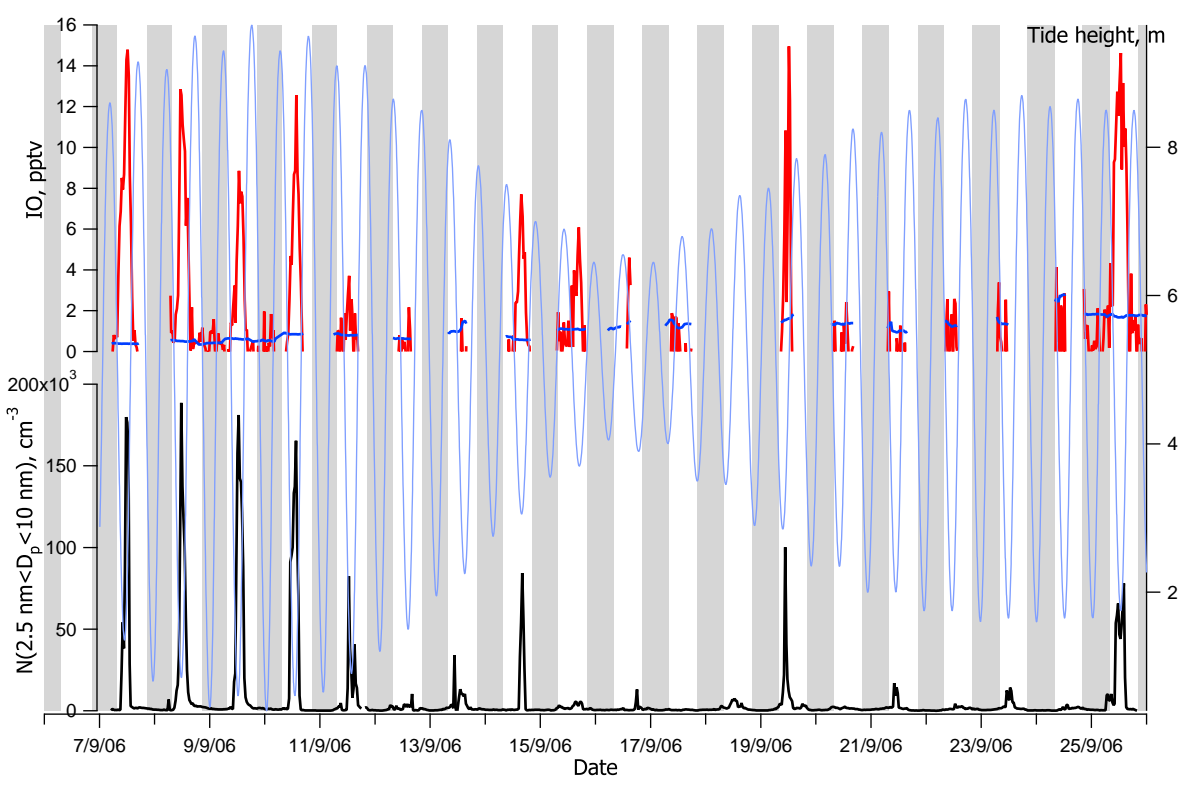

Fig. 10. In situ $30 \mathrm{~min}$ averaged LIF-measured IO mixing ratios (red trace, top panel with associated LOD in thick blue) and 30 minute averaged particle concentrations between 2.5 and $10 \mathrm{~nm}$ diameter (bottom panel) with superimposed tidal height in metres (right axis); day and night indicated by shaded stripes.
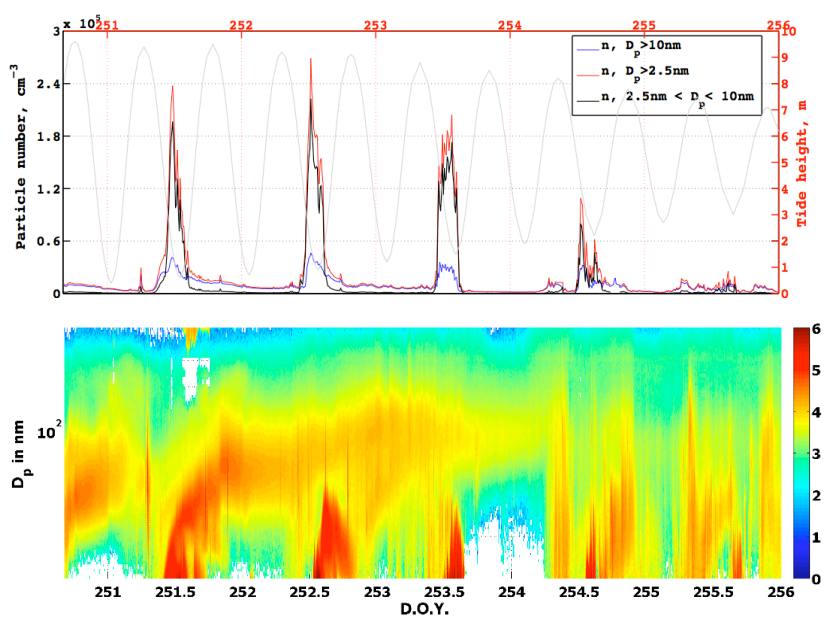

Fig. 11. Top panel: one minute averaged particle concentrations above $2.5 \mathrm{~nm}$ diameter from TSI 3776 (red trace), above $10 \mathrm{~nm}$ diameter from TSI 3010 (blue trace) and between 2.5 and $10 \mathrm{~nm}$ diameter by difference (black trace, all left axis) with superimposed tidal height in metres (right, red axis). Bottom panel: SMPSmeasured particle size distributions; the colourbar is in units of $\log \left(d N / d \log D_{p}\right)$. Particle growth may be inferred from the in situ observations of continuous increase in particle size, particularly from the particle formation events observed on 8 and 9 September (DOY 251 and 252). Inferred growth to several tens of nm is observed on many of the days and the increase in number in the SMPS distribution from $10 \mathrm{~nm}$ directly follows from the increase in $2.5 \mathrm{~nm}$ particles and subsequent appearance of $10 \mathrm{~nm}$ particles observed by the CPCs. of the CPCs at their lower size cut-off (see Sect. 4.3). At Mace Head, Dal Maso et al. (2002) estimated a range of 120$180 \mathrm{nmh}^{-1}$ in clean marine air and $15-20 \mathrm{nmh}^{-1}$ in polluted air advected over a tidal zone. The site at Roscoff is more complex than Mace Head with sources at various distances upwind (see Leigh et al., 2009, for a seaweed map and footprint analysis) as well as numerous pollution sources. However, it is apparent that the growth rates at the two locations are of similar orders of magnitude.

\subsection{Micrometeorological measurements}

The $u, v$ and $w$ components of windspeed, $T$ and $\mathrm{RH}$ were continuously measured at high frequency (see Sect. 4.4) for the entire month of September 2006. The meteorological criteria for the flux measurement validity were more strict than for the other measurements. A prolonged seaward fetch is necessary for flux determination and, owing to the location of the flux boom on the Northwesterly facing side of the jetty, the wind direction for valid flux determination was limited to the sector between $215^{\circ}$ and $005^{\circ}$. After data rejection to comply with this and other quality assurance criteria, 330 15-min flux integration periods remained over the project.

\subsection{1 $\mathrm{O}_{3}$ fluxes and derived deposition velocities}

Whitehead et al. (2009b) provide a detailed discussion of the $\mathrm{O}_{3}$ fluxes. Briefly, the $\mathrm{O}_{3}$ flux was measured to range from $-3.4 \mathrm{mgm}^{-2} \mathrm{~s}^{-1}$ to $1.0 \mathrm{mgm}^{-2} \mathrm{~s}^{-1}$ (where negative values denote downward flux) with a mean of $-0.060 \pm 0.014 \mathrm{mgm}^{-2} \mathrm{~s}^{-1}$ (standard error). The 


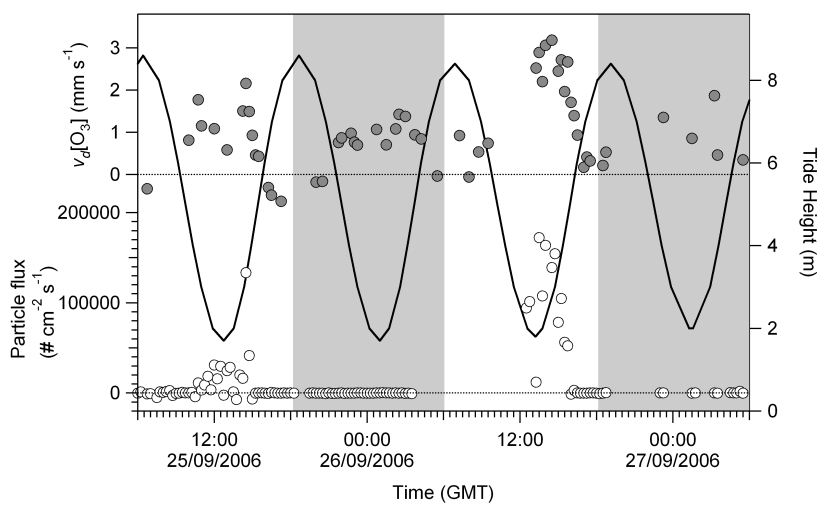

Fig. 12. Ozone deposition velocities calculated from measured fluxes along with apparent ultrafine particle emission fluxes for 25 to 27 September

corresponding mean ozone deposition velocity $\left(v_{d}\left[\mathrm{O}_{3}\right]\right)$ was $0.96 \mathrm{mms}^{-1}$ with a standard error of $\pm 0.15 \mathrm{mms}^{-1}$ (where deposition is denoted by a positive value). During periods of valid flux measurements, $v_{d}\left[\mathrm{O}_{3}\right]$ was more than four times greater $\left(\right.$ mean $=1.28 \mathrm{mms}^{-1}$ ) during low tide (defined as when the sea floor was exposed at a tide height $<5.6 \mathrm{~m}$ ) than during high tide (mean $=0.302 \mathrm{mms}^{-1}$ ). In a period of large tidal amplitude between 24 and 28 September, nighttime low tide $v_{d}\left[\mathrm{O}_{3}\right]$ at $1.00 \pm 0.10 \mathrm{mms}^{-1}$ was significantly lower than that during daytime low tide $\left(2.05 \pm 0.16 \mathrm{mms}^{-1}\right)$ but still significantly higher than high tide $v_{d}\left[\mathrm{O}_{3}\right]$. The filled circles in Fig. 12 shows ozone deposition values derived from the measurements across two days in this period. A similar statistically-significant relationship was seen during the period of smaller tidal amplitude between 14 and 18 September, though with lower absolute differences.

\subsubsection{Particle number fluxes}

The period of spring tides between the 7 to the 11 September corresponded to Northeasterly winds crossing the infralittoral zone, but beyond the fetch for reliable flux measurements. Good fetch and stationary conditions were observed on the 25 and 26 September, during which one minute averaged bursts of up to $10^{5}$ particles $\mathrm{cm}^{-3}$ were observed during daytime low tide. The corresponding net particle emission fluxes of up to $2 \times 10^{5}$ particles $\mathrm{cm}^{-2} \mathrm{~s}^{-1}$ can be seen in the open symbols in Fig. 12 alongside the highest values of $v_{d}\left[\mathrm{O}_{3}\right]$ (up to $3 \mathrm{mms}^{-1}$ ). Significant particle concentrations or emission fluxes were never observed during nighttime low tides.

\subsubsection{Concentration footprints}

Concentration footprints were calculated for a range of wind velocities and representative meteorological conditions using the analytical approximation of the advection-diffusion equations reported by Schmid (1994). The heterogeneity of the upwind surface makes it difficult to draw firm conclusions about the exact form of the footprint, but the model can provide broad estimates of the concentration footprint for the range of conditions encountered during the RHaMBLe experiment. Figure 13 illustrates the concentration footprints for a range of typical wind speeds under representative daytime and night-time stability conditions with roughness lengths corresponding to low and high-tide conditions. The contours define the envelopes containing the denoted percentage contributions to the concentration measured at the receptor point. Warmer colours denote the areas of low local contribution to the received concentrations; successively cooler colours denote increasing cumulative contribution to the received concentration. These footprints were used in the interpretation of heterogeneity in the model study reported in Leigh et al. (2009) and summarised in Sect. 7.2.

\subsection{Macroalgal $I_{2}$ emissions}

During the Roscoff field deployment, simultaneous laboratory emission experiments were conducted at SBR with an aim to construct an emission profile for molecular $\mathrm{I}_{2}$ from a range of kelps and fucoids found in the intertidal range and the surrounding shallow waters. Ball et al. (2009) presents full details of these studies. Briefly, direct spectroscopic quantification of gas-phase $\mathrm{I}_{2}$ was made with a detection limit of $\sim 25 \mathrm{pptv}$ in $7.5 \mathrm{~s}$, identifying substantial emissions from Ascophyllum nodosum, Saccharina latissima, Laminaria digitata and Laminaria hyperborea, whereas $\mathrm{I}_{2}$ was at or below the detection limit for Fucoids (F. vesiculosus and $F$. serratus). Emission rates were estimated taking account of sample mass (in units of $\mathrm{pmol} / \mathrm{min} / \mathrm{gFW}$ ) and were found to show substantial species to species variation: the largest emitters, $L$. digitata and $L$. hyperborea, produced up to 3.5 orders of magnitude greater $\mathrm{I}_{2}$ emission than the fucoids, which were the smallest emitters. Further stress experiments were carried out on fragments of $L$. digitata, showing $I_{2}$ emissions with all forms of stressing, but particle formation was only observed in the presence of both ozone and room light.

\section{Interpretation and discussion}

\subsection{Sources of reactive inorganic iodine}

As reported in Jones et al. (2009), the combined midday I atom flux from the photolabile dihalomethanes $\mathrm{CH}_{2} \mathrm{I}_{2}$, $\mathrm{CH}_{2} \mathrm{IBr}$ and $\mathrm{CH}_{2} \mathrm{ICl}$ of $\sim 5 \times 10^{3}$ atom $\mathrm{cm}^{-3} \mathrm{~s}^{-1}$ is several orders of magnitude lower than the estimated I atom flux from $\mathrm{I}_{2}$ based on coinciding measurements at the site $\left(\sim 10^{7}-\right.$ $10^{8}$ atom $\mathrm{cm}^{-3} \mathrm{~s}^{-1}$ ), indicating that at Roscoff the major I atom precursor was $I_{2}$ rather than reactive iodocarbons. In order to investigate whether any spatial heterogeneity in reactive inorganic iodine concentrations or in particle formation, 


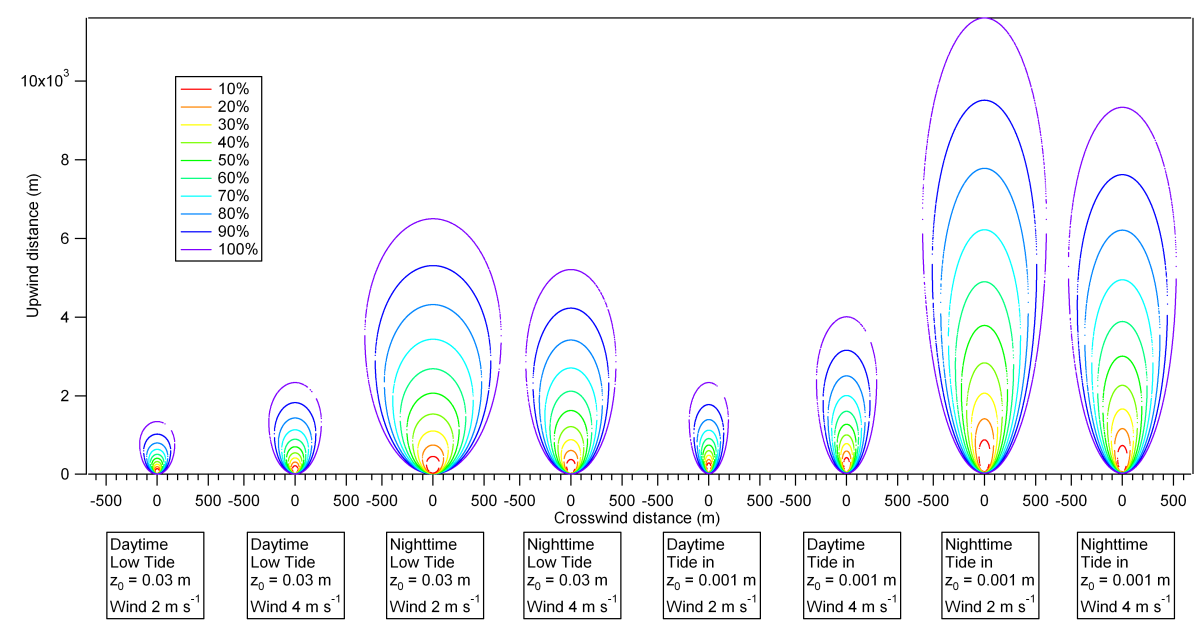

Fig. 13. Concentration footprints calculated for a range of windspeeds for roughness lengths broadly corresponding to low and high tidal surface and for representative daytime and night-time stability conditions.

or to establish the necessity to invoke chemical explanations for any differences between path-integrated or in situ observations, it is first necessary to investigate the spatial distribution of the sources of molecular iodine.

\subsection{Spatial heterogeneity and diurnal variability considerations}

It is clear that there are discrepancies outside the instrument error between LP-DOAS and in situ measurements of iodine species that must be reconciled by a physical explanation. The peak LP-DOAS IO mixing ratios, ranging from $4.8 \mathrm{pptv}$ to $10.1 \mathrm{pptv}$ with a mean of $7.5 \mathrm{pptv}$, was significantly lower than the in situ measurements reported in Furneaux et al. (2009) and Wada et al. (2007) of 27.6 pptv and 54 pptv respectively. However, the discrepancy appears to be dependent on conditions (see the lower inset panel in Fig. 8), particularly wind direction. This is unsurprising given the heterogeneity of the macroalgal distribution. Discrepancies might be expected to be even more evident in the case of the directly emitted $\mathrm{I}_{2}$. Whilst IO, $\mathrm{I}_{2}$ and OIO all have very short photolytic lifetimes, IO is efficiently regenerated from its photolysis product (atomic iodine) by very rapid reaction with $\mathrm{O}_{3}$, and the IO/I couplet is persistent, significantly extending the apparent IO lifetime. In the absence of a means of regenerating $I_{2}$ one might expect extremely different concentrations in the path-integrated and in situ measurements owing to the source heterogeneity and photolysis. Mahajan et al. (2009a) used a 1-D model with a prescribed $\mathrm{I}_{2}$ injection pulse to explore the chemistry (see Sect. 7.3, below) required to replicate the measured path-integrated $\mathrm{I}_{2}$ and IO concentrations making an assumption that the iodine species were confined to $30 \%$ of the light-path. This compares with the assumption of $8 \%$ of the path made in Saiz-Lopez et al. (2006) for the macroalgal source contribution at Mace Head.
The spatial variability in IO emissions was examined through the different viewing angles of the CMAX-DOAS instrument. Differential slant column densities of IO measured by the CMAX-DOAS during low tides from 13 to 28 September are shown in Fig. 9, plotted by wind direction and coloured by the $\mathrm{I}_{2}$ photolysis frequency at the time of measurement. The increase in DSCD from the $2^{\circ}$ to $5^{\circ}$ views is shown in the top two panels. Furthermore, the highest concentrations are seen in the Northerly and Easterly $5^{\circ}$ elevation views in a Northwesterly wind. This is compatible with major emission sources behind the Île de Batz, with the increased concentrations in the Easterly view suggesting either increased emissions reaching sufficient altitude above the surface to be measurable, or downwind formation of IO. There is no clear dependence of concentrations on actinic flux. Considered as a function of windspeed rather than $\mathrm{j}_{\mathrm{I}_{2}}$, the modest windspeeds $\left(2 \mathrm{~ms}^{-1}\right)$ are associated with the highest DSCDs of IO in the $5^{\circ}$ views. As these views are several tens or hundreds of metres above the surface by the time the line of sight is over the Île de Batz and the associated macroalgal source regions, this may be expected, as the faster winds will not allow emissions to be lofted into the line of sight. For the $2^{\circ}$ view, the slightly higher winds produce the largest DSCDs, as a result of their larger footprints.

Useful constraint on the assumptions employed in modelling the $\mathrm{I}_{2}$ and IO at Roscoff can be made by reference to the map of macroalgal distribution, their emission rates and the concentration footprints. Leigh et al. (2009) describe the development and use of a model using footprints calculated over a range of windspeeds and tidal heights in order to calculate transport of emissions of $I_{2}$ from the various mapped macroalgal species using their specific emissions after Ball et al. (2009). Footprints were interpolated to ensure smooth transition from each calculated footprint scenario and wind direction was used to rotate the footprint accordingly. The 


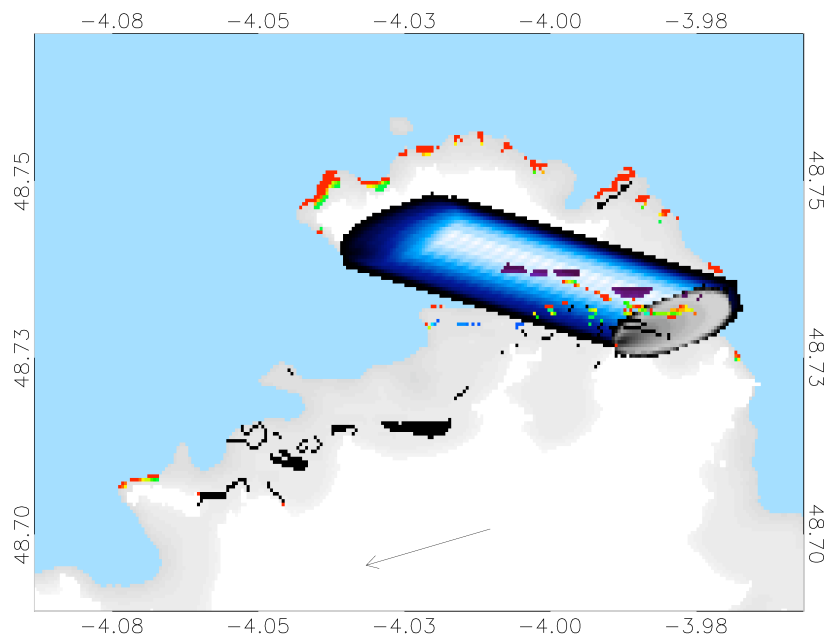

Fig. 14. Modelled coverage and emissions of molecular iodine in the Roscoff region during an ebb tide at 9.42 am on 7 th September, with the tide $0.04 \mathrm{~m}$ below the datum. Also shown are calculated site footprint (grey) and LP-DOAS footprint (blue) at a windspeed of $7.26 \mathrm{~m} / \mathrm{s}$ and direction of $73.7^{\circ}$. Emissions coloured red represent recently exposed Laminaria beds emitting $1 \times 10^{17}$ molecules per second per $0.0005^{\circ} \times 0.0005^{\circ}$ grid square.

footprint was superimposed on the $I_{2}$ emission grid to estimate the concentration at the site, and by integration of the footprints convolved to the emission function along its line of sight, to calculate the concentration measured by the LP-DOAS. Figure 14 shows an example of the instantaneous calculated footprints superimposed onto the macroalgal exposure map convolved with their specific emission rates for a single timestep of the model. The concentrations were calculated by allowing photolysis and both photolysis and $\mathrm{I}_{2}$ recycling at various rates (as postulated in Mahajan et al., 2009a) in separate simulations. Since it was only possible to obtain $\left[\mathrm{I}_{2}\right]$ comparable with measured concentrations by unphysically disallowing photolysis in the model, it may be inferred that the $\mathrm{I}_{2}$ emissions were even higher than produced by the mapped input emissions. Leigh et al. (2009) hypothesise that a candidate for the discrepancy may be an underestimated emission from the patchily distributed Laminaria ochroleuca, a species with uncertain emission rates, or alternatively from very local sources including patches of Ascophyllum nodosum, too small to be resolved by the emission map.

\subsection{Halogens in the presence of pollution}

Possibly the most surprising element of the findings from the RHaMBLe Roscoff deployment was the persistence of reactive iodine and bromine chemistry (and associated particle formation) under the pertaining moderately polluted conditions. Until recently, it has been assumed on the basis of the laboratory-measured kinetic rate constants that reactive ma- rine halogen chemistry would be unlikely to persist in the presence of significant concentrations of $\mathrm{NO}_{\mathrm{x}}$ and that it was likely to be limited to the remote MBL or relatively clean coastal locations. This is the result of rapid reaction of $\mathrm{XO}$ with $\mathrm{NO}_{2}$ short-circuiting the regeneration of halogen atoms by XO photolysis.

In order to explain their observations of high levels of IO and OIO in the polluted Gulf of Maine atmosphere, Stutz et al. (2007) proposed that $\mathrm{IONO}_{2}$ reacts with $\mathrm{O}_{3}$ to form OIO. Kaltsoyannis and Plane (2008) calculated that IONO2 and I will recycle rapidly back to $\mathrm{I}_{2}$ and further calculated that $\mathrm{I}$ atoms formed from $\mathrm{I}_{2}$ photolysis would preferentially react with $\mathrm{IONO}_{2}$ than $\mathrm{O}_{3}$ if $\left[\mathrm{O}_{3}\right] /\left[\mathrm{IONO}_{2}\right] \gtrsim 0.01$, thus limiting build up of $\mathrm{IONO}_{2}$. Employing the assumptions described in Sect. 7.2 above, Mahajan et al. (2009a) concluded that such a mechanism for recycling $\mathrm{I}_{2}$ is required and postulated that the reaction $\mathrm{IONO}_{2}+\mathrm{I} \rightarrow \mathrm{I}_{2}+\mathrm{NO}_{3}$, proceeding with a reaction rate of $\geq 2 \times 10^{-11} \mathrm{~cm}^{3}$ molecule ${ }^{-1} \mathrm{~s}^{-1}$, could explain the observations using the assumed $\mathrm{I}_{2}$ source. The Leigh et al. (2009) study found that recycling was insufficient when driven by the derived macroalgal $\mathrm{I}_{2}$ sources and an additional source was likely required. Alternatively, an even larger $\mathrm{I}_{2}$ source enhancement with appropriate heterogeneity but without the recycling could explain the observations.

There is no known comparable recycling mechanisms for OIO and its rapid loss to photolysis and aerosol uptake (either to nucleation or condensation) will only be offset by the IO self-reaction or reaction of $\mathrm{IO}$ with $\mathrm{BrO}$ and will not be expected to be observed during daylight in the absence of a very strong local primary source directly at the measurement location. This was indeed found to be the case in Roscoff.

The LP-DOAS observation of up to $3.0 \mathrm{pptv} \pm 0.9 \mathrm{pptv}$ IO, and by LIF of 1 to 2 pptv, at night under the polluted conditions and the observations of elevated LP-DOAS $\mathrm{NO}_{3}$ and BBCEAS and $\Sigma\left(\mathrm{NO}_{3}+\mathrm{N}_{2} \mathrm{O}_{5}\right)$ provide support for a source of IO from the reaction $\mathrm{I}_{2}+\mathrm{NO}_{3} \rightarrow \mathrm{IONO}_{2}+\mathrm{I}$ followed by $\mathrm{I}+\mathrm{O}_{3} \rightarrow$ IO. In all daytime and night time cases, one might expect a significant perturbation to $\mathrm{HO}_{\mathrm{x}}$ chemistry (see Sect. 7.4, below). In order to fully investigate the vertical distribution of speciated gaseous and size-resolved halogen species at Roscoff driven by the heterogeneous $\mathrm{I}_{2}$ source distribution and to explore the coupling between $\mathrm{HO}_{\mathrm{x}}$ and XO chemistry, the incorporation of the model of sizeresolved aerosol activation described by Lowe et al. (2009) into a 1-D vertical framework is ongoing.

\subsection{Impacts of reactive halogens on radicals in the polluted atmosphere}

The observed levels of $\mathrm{IO}$ and $\mathrm{BrO}$ will provide a two step route for conversion of $\mathrm{HO}_{2}$ to $\mathrm{OH}$ that occurs alongside other gas-phase conversion reactions, for example $\mathrm{HO}_{2}+\mathrm{O}_{3}$ (R3) and, in more polluted environments, $\mathrm{HO}_{2}+\mathrm{NO}$ and as a result have been shown to increase the oxidative capacity at coastal sites where they prevail. Previous modelling studies 
of background (low $\mathrm{NO}_{\mathrm{x}}$ ) air-masses (e.g Stutz et al., 1999; Bloss et al., 2005; Read et al., 2008; Whalley et al., 2010) have found that the presence of IO leads to an enhancement in $\mathrm{OH}$. At Roscoff, a semi-polluted $\mathrm{NO}_{\mathrm{x}}$-influenced site, reaction of IO with $\mathrm{NO}$ and $\mathrm{NO}_{2}$ is also significant, causing a decrease in the NO-mediated $\mathrm{HO}_{2}$ to $\mathrm{OH}$ conversion and so the impact of $\mathrm{XO}$ upon $\mathrm{HO}_{\mathrm{x}}$ becomes less clear-cut. Furneaux et al. (2009) demonstrated that under steady state conditions an IO compensation point exists, where the incease in $\mathrm{OH}$ driven by IO maximises; at $0.4 \mathrm{ppb} \mathrm{NO}_{\mathrm{x}}$ typical of the RhaMBle observations this level was found to be 15 pptv, such that $\mathrm{OH}$ levels in the Roscoff site vicinity may actually be reduced by the halogen processing, depending upon the $\mathrm{IONO}_{2}$ recycling rate assumed, as discussed above.

Iodine and bromine reactions lead to rapid and efficient ozone loss, however the short transit time between iodine emission regions and the measurement locations in the Roscoff experiment, and the limited lifetime of gas-phase inorganic iodine species, did not permit substanital ozone depletion to be observed. 1-D modelling simulations performed by Mahajan et al. (2009a) derived a halogen-driven ozone reduction of $1.5 \mathrm{ppbv}$ or $5 \%$ in the lowermost region of the boundary layer above the iodine emission source regions, with $\mathrm{O}_{3}$ levels rapidly replenished by dilution from air aloft on a timescale of 5-10 min. This situation may be contrasted with halogen-driven ozone depletion over the open ocean, where levels of inorganic halogens and their precursors are much lower than in the coastal RhAMBLe experiment, but as the active region is spatially extensive appreciable reductions in boundary layer ozone may result (Read et al., 2008).

\subsection{Particle flux and concentration relationship}

The particles observed in the daytime low tide bursts are not directly emitted, but are the product of gaseous photochemistry followed by a first order phase transition. The micrometeorological fluxes are therefore "apparent" emission fluxes which must take into account the photochemistry that takes place below the height of the flux boom within the flux footprint. There may also be photochemistry above the measurement height and this would lead to an underestimate of the apparent emission flux such that the reported values are lower limits to particle formation. In any case, the reported values are large and are always associated with enhanced apparent ozone depositional flux; apparent because net photochemical destruction below the boom height will be added to the direct depositional loss in contributing to the measured values. The high apparent particle emission fluxes result in the very high measured concentrations of particles between 2.5 (or 3) $\mathrm{nm}$ and $10 \mathrm{~nm}$ diameter. As discussed in Sect. 7.6 below, the particles are formed more rapidly than they are lost, hence leading to their detection. They are probably formed in hotspots along the airmass trajectory each contributing to the number concentration as they dilute into the background air. Flanagan et al. (2005) derived a relationship between the calculated ultrafine particle fluxes and their simultaneously measured concentrations in simple "single-source" particle burst events. Such a relationship may be extremely useful in inferring fluxes from concentration measurements at other locations under similar conditions. However, there would appear to be no reason to expect such a relationship to apply under conditions of significant source heterogeneity or continuous source contribution. It is surprising, therefore, that a statistically significant correlation has been observed and reported for the measurements during RHaMBLe at Roscoff in Whitehead et al. (2009b) as:

$\log _{10} F=1.56 \log _{10} N-2.78$

where $F$ and $N$ are the flux and number concentrations respectively. Given the heterogeneous macroalgal distribution within the variable footprints (see Leigh et al., 2009, for a discussion), the reason for this relationship is unclear and should be the focus of further work. The directly measured peak fluxes in Mace Head reported by Flanagan et al. (2005) were between $10^{5}$ and $10^{6}$ particles $\mathrm{cm}^{-2} \mathrm{~s}^{-1}$ and are directly comparable to the value of $2 \times 10^{5}$ particles $\mathrm{cm}^{-2} \mathrm{~s}^{-1}$ reported by Whitehead et al. (2009a).

\subsection{A mechanistic interpretation of the combined measurements}

Whilst there have been a number of surprises and novel findings during the Roscoff experiment, all are consistent with the existing hypotheses of coastal particle formation from macroalgal iodine emissions under low tidal exposure. Very high local $\mathrm{I}_{2}$ concentrations will result from the emission flux from various intertidal macroalgal species on exposure to the atmosphere at low tide (for example, Ball et al. (2009) report $I_{2}$ mixing ratios of up to $25 \mathrm{ppbv}$ and 15 to $85 \mathrm{ppbv}$ from Laminaria digitata and Laminaria hyperborea and previous studies (Bale et al., 2009; Dixneuf et al., 2009) observed up to several hundred ppbv $\mathrm{I}_{2}$ ). Ozone deposition is enhanced at low tide, either at night or during the day, relative to high tidal deposition (Whitehead et al., 2009b). During the day there will be a component of this apparent deposition enhancement resulting from $\mathrm{O}_{3}$ consumption by iodine photochemistry below the measurement height of the flux boom. This explains the enhancement of the apparent daytime low tide flux over the night time flux. At night, the depositional flux enhancement will either be the result of direct deposition to the exposed macroalgae or night time chemistry below the boom height. There is no likely candidate mechanism for the latter explanation and direct deposition is consistent with the deposition reported by Palmer et al. (2005) and Küpper et al. (2008) in their laboratory experiments. This ozone stimulation will result in enhanced $\mathrm{I}_{2}$ emission from the macroalgae (see Ball et al. (2009) for a characterisation of the emissions from various species and Küpper et al. (2008) for a postulated biological mechanism). 
Owing to the short photolytic lifetime of $\mathrm{I}_{2}$, during daylight there will be a very high local formation rate of atomic iodine and iodine monoxide. The IO/I couplet will persist in rapidly-attained photostationary state with a bleed out from the system to $\mathrm{HOI}, \mathrm{IONO}_{2}$ and the self-reaction products of IO (the bleed to $\mathrm{IONO}_{2}$ will be reduced if short-circuited by the reaction with atomic iodine to regenerate $I_{2}$ postulated by Mahajan et al. (2009a)). The formation of the former two will be slow relative to the self-reaction at the very high iodine concentrations in the immediate vicinity of the emissions, owing to the low magnitudes of $k_{\mathrm{IO}+\mathrm{NO}_{2}}[\mathrm{IO}]\left[\mathrm{NO}_{2}\right]$ and $k_{\mathrm{IO}+\mathrm{HO}_{2}}[\mathrm{IO}]\left[\mathrm{HO}_{2}\right]$ relative to $k_{\mathrm{IO}+\mathrm{IO}}[\mathrm{IO}]^{2}$ even under moderate $\mathrm{NO}_{2}$ concentrations. This will allow formation of particles from the $\mathrm{I}_{\mathrm{x}} \mathrm{O}_{\mathrm{y}}$ in the "cloud" of iodine oxide vapours in this daytime emission hotspot. The dilution of the high iodine vapour concentrations into the background semi-polluted air will rapidly increase the rate of the IO loss to reaction with $\mathrm{HO}_{2}$ and $\mathrm{NO}_{2}$ (both first order in $\mathrm{IO}$ ) relative to the self-reaction (second order in $\mathrm{IO}$ ). The $\mathrm{I}_{2}$ will reduce rapidly by both dilution and photolysis during daylight and by dilution alone at night. The IO/I couplet will have a continuous but reducing source from the photolysing $\mathrm{I}_{2}$ during daylight, but not at night.

Air parcels passing over multiple source regions (macroalgal beds) will have multiple injections of reactive iodine at different times prior to reaching either the LP-DOAS light path or the in situ measurement site or crossing the CMAXDOAS slant column. This will impact differently on the measurement of $\mathrm{I}_{2}$ and IO using the different sampling geometries, see Fig. 8. Formation of OIO and higher $\mathrm{I}_{\mathrm{x}} \mathrm{O}_{\mathrm{y}}$ species will reduce very rapidly on dilution (having a second order and higher order dependance on [IO], respectively), and OIO, at least, will rapidly photolyse (hence it is observed only under very reduced light levels). Particle formation, which would be very high order in [OIO], will rapidly cease on dilution in daylight; the source of OIO, second order in IO, only being able overcome its photolytic loss (and hence to sustain particle production) very close to the macroalgal emissions. Those particles that are already formed will be subject to loss by diffusion and coagulation. Working backwards from the peak concentration observed on 8 September of $250000 \mathrm{~cm}^{-3}$, assuming that these are all contained in a single nucleation mode between 2.5 and $10 \mathrm{~nm}$ diameter tending towards zero at the instrument cut-offs, the polydisperse coagulation half-life will have been of the order of tens of minutes. The measured number is the minimum that will have survived at a distance downwind of the source hotspots comparable to the distance to the measurement site under the correct wind direction (since there may be an indeterminable number of particles below detectable size) and that will be available for growth by condensation of available vapours. Under conditions where the air is advected offshore, the particle input resulting from macroalgal emissions will be the last injection of significant numbers of particles into a continentally-influenced airmass. With growth rates of $>10 \mathrm{~nm} \mathrm{hr}^{-1}$ as inferred from the observations and only modest loss rates, the coastal new particles will comprise a large fraction of the population that will subsequently be available to act as $\mathrm{CCN}$ when exposed to water supersaturation. The exact magnitude should be the subject of targeted model investigation.

It may at first appear counterintuitive that pollution may enhance the importance of coastal nucleation, but it is likely to be the case under such circumstances. Pre-existing particle surface area in the polluted background air may be sufficient to scavenge available condensable material, so suppressing nucleation of new particles, at vapour concentrations that might be reasonably expected in such airmasses. However, this same pre-existing condensation sink will likely be incapable of suppressing nucleation at the extremely high hotspot sources of condensable $\mathrm{I}_{\mathrm{x}} \mathrm{O}_{\mathrm{y}}$ compounds. On dilution of these hotspot "micro-plumes" into the background polluted air, the number concentration of particles will be significantly enhanced (although the exact magnitude of the competing processes is difficult to quantify without knowledge of the relative dependence of nucleation and condensation rates on nucleating vapour concentration and the rate of dilution, i.e. the exposure time to the hotspot, plume buoyancy and entrainment rate). As the "micro-plumes" dilute, the supply of newly-formed condensable iodine vapours $\left(\mathrm{I}_{\mathrm{x}} \mathrm{O}_{\mathrm{y}}\right.$, formed at a high order rate of [IO]) will be much reduced, but the additional particles will experience growth in the condensable products of oxidative chemistry in the polluted air (e.g. organic compounds, $\mathrm{HNO}_{3}$ or $\mathrm{H}_{2} \mathrm{SO}_{4}$ ). Even in the cleaner Mace Head particle formation events during PARFORCE, there is an indication from the contemporaneous reduction in measured gaseous $\mathrm{H}_{2} \mathrm{SO}_{4}$ concentration, the increase in nucleation mode surface area and increase in nucleation mode hygroscopicity that $\mathrm{H}_{2} \mathrm{SO}_{4}$ may act as additional condensing material in the growth of particles, once formed.

\subsection{Coastal particle behaviour as $\mathrm{CCN}$}

The growth of the newly formed particles that may be inferred from Fig. 11 over a period of several days provides an indication that the particles may be of local or potentially regional radiative importance. As discussed in Sect. 7.6 above, the growth to greater than $100 \mathrm{~nm}$ diameter is likely to involve the condensation of non-iodine-containing condensable material as the micro-plumes containing high ultrafine particles dilute into the semi-polluted background air. Whilst the condensation of this material will contribute most of the particle mass, the massive enhancement of the particle number is clearly solely the result of the nucleation of material formed from macroalgal emissions of $\mathrm{I}_{2}$. Even above $100 \mathrm{~nm}$ diameter, the particles are not sufficiently large to contribute to the direct scattering burden, but may contribute to the indirect radiative budget by significantly enhancing the potential number of $\mathrm{CCN}$ at supersaturations corresponding to reasonable marine updraught velocities. The number of 
$\mathrm{CCN}$ that activate into cloud droplets directly controls the brightness of a cloud and will play a role in determining its persistence and the onset of rainfall and the ability of a particle to act as a CCN is directly determined by its size and composition; a larger, more-soluble particle will be more efficient than a smaller less-soluble one. A full discussion of the properties determining the behaviour of aerosol particles as CCN is provided in McFiggans et al. (2006). Whilst the particles may be large enough to participate in the competition for water vapour that occurs as an air parcel moves into supersaturation; their degree of success in this competition depends on the number and size of the other particles and their composition. If the hypothesis of micro-plume particle formation, subsequent dilution and growth in the background semi-polluted air is correct, the composition of the initially formed particles will have no significant impact on the ability to act as a CCN under representative MBL conditions. This is because only the minority of the particle mass is contributed by the macroalgal iodine emissions by the time they have reached $\mathrm{CCN}$ sizes under the conditions experienced in the RHaMBLe experiment.

\section{Conclusions and future work}

It has been clearly demonstrated that iodine-mediated coastal particle formation is not a phenomenon unique to the West coast of Ireland and the particle bursts observed at Roscoff during the RHaMBLe project share many of the characterisatics of those observed during previous projects at Mace Head despite the many differences between the locations. In situ measured ultrafine particle concentrations are strongly correlated with in situ concentrations of the rapidly recycled reactive iodine species, IO. Both have a very strong daytime low tide signature, entirely consistent with the emission of molecular iodine by macroalgal species fully or partially exposed by the receding waterline. Even the shortest lived iodocarbons at their measured concentrations produce several orders of magnitude lower iodine atom flux than that from the photolysis of molecular iodine. Frequently the emitted $\mathrm{I}_{2}$ has reacted to below detectable levels by the time air has reached the measurement location, although measurable concentrations of IO are still present owing to the rapid recycling. The rapid iodine chemistry will significantly perturb the background radical budget though, in contrast to Mace Head, the presence of significant anthropogenic $\mathrm{NO}_{\mathrm{x}}$ leads to less clear impacts on the $\mathrm{HO}_{2}$ : $\mathrm{OH}$ ratio than has previously been seen.

The macroalgal sources at Roscoff are very heterogeneous and this leads to differences in the relative concentrations of iodine species observed by path-integrated and in situ measurement techniques. The path-integrated $\mathrm{I}_{2}$ can be explained by $\mathrm{NO}_{\mathrm{x}}$-mediated iodine atom recycling through $\mathrm{IONO}_{2}$, or elevated and highly heterogeneous molecular iodine sources. A macroalgal distribution map, coupled to species-dependent
$\mathrm{I}_{2}$ emission factors from incubation experiments, high resolution bathymetry and tide tables is able to capture significant variability in measured $\mathrm{I}_{2}$. Path-integrated IO concentrations are generally lower than those measured by in situ techniques, but are sometimes comparable, indicating that the emission sources contributing to each measurement are variable depending on wind direction.

The apparent particle emission fluxes leading to the elevated low tidal concentrations at Roscoff were shown to be associated with an enhanced apparent depositional flux of ozone, consistent with both a direct $\mathrm{O}_{3}$ deposition to macroalgae and a photochemical involvement of $\mathrm{O}_{3}$ in particle formation. Both are unsurprising but not previously shown by direct flux measurements. The surprising fact was the strong correlation between particle flux and particle concentration under such heterogeneous conditions, providing a means of estimating fluxes from concentration. The vigour of the particle formation events was observed to be greatest at the lowest tides. Concentrations of particles between 3 and $10 \mathrm{~nm}$ diameter were significantly higher than during more moderate low tides and particles grew to much larger sizes. Large-scale particle growth to diameters in excess of $100 \mathrm{~nm}$ may be inferred from the size distribution measurements during and following these low-tidal periods, indicating that the particles could act as cloud condensation nuclei given reasonable atmospheric supersaturations. In such a way, the very large injection of freshly-formed particles into air advecting offshore or onshore have the potential to significantly impact on the local or regional radiative budget. It is very likely the particles in Roscoff only grew to sizes at which they became $\mathrm{CCN}$ active by the condensation of anthropogenically-formed condensable material. Any such impact on the radiative budget therefore constitutes a forcing.

There are several remaining questions before the coastal particle phenomenon can be closed. At a process level, the exact species participating in the nucleation and condensational growth is still yet to be resolved, though it is not difficult to photochemically induce nucleation at levels of $\mathrm{I}_{2} \mathrm{ob}-$ served in the macroalgal exposure experiments. The roles of anthropogenic condensable components on particle growth should be characterised, probably by in situ compositional analysis and, whilst it is probably safe to assume that 100 to $120 \mathrm{~nm}$ particles may be $\mathrm{CCN}$ active at reasonable supersaturations, this should be verified by direct measurement. In order to establish the frequency and magnitude of any radiative impacts, a longer term climatology of particle size distributions should be established, the duration of periods of growth from particle formation events being used to infer the spatial scale of the process. Finally, in order to establish how widespread the phenomenon is likely to be, it would be desirable to establish some proxy for the scale and distribution of the macroalgal sources that can be monitored by remote sensing. 
Acknowledgements. This work was supported by the NERC UK SOLAS programme under the "Reactive Halogens in the Marine Boundary Layer" (RHaMBLe) grant number NE/D006570/1. Results were presented through the "Integration \& synthesis of current research into the formation, evolution and roles of cloud condensation nuclei in the marine environment" (UK SOLAS CCN Knowledge Transfer) activity (NE/G000247/1). JDL, DEH, TI, LKW were all supported in part or in whole by UK National Centre for Atmospheric Sciences (NCAS) funding. ASM thanks the School of Chemistry, University of Leeds for his Ph.D studentship. Leicester and Cambridge Universities participated courtesy of NERC grant number NE/D00652X/1. This is a contribution to SOLAS and the SOLAS/IGAC task Halogens in the Troposphere (HitT). We would like to thank Bernard Kloareg, the staff of Station Biologique and all the people of Roscoff for making us so welcome. The RHaMBLe experiment would not have been possible without them.

Edited by: W. T. Sturges

\section{References}

Alicke, B., Hebestreit, K., Stutz, J., and Platt, U.: Iodine oxide in the marine boundary layer, Nature, 397, 572-573, 1999.

Allan, B. J., McFiggans, G., Plane, J. M. C., and Coe, H.: Observations of iodine monoxide in the remote marine boundary layer, $\mathrm{J}$. Geophys. Res., 105, 14361-14369, 2000.

Bajjouk, T., Guillaumont, B., and Populus, J.: Application of Airborne Imaging Spectrometry System Data to Intertidal Seaweed Classification and Mapping, Hydrobiologia, 327, 463-471, 1996.

Bale, C. S. E., Ingham, T., Commane, R., Heard, D. E., and Bloss, W. J.: Novel measurements of atmospheric iodine species by resonance fluorescence, J. Atmos. Chem., 60, 51-70, 2008.

Ball, S. M. and Jones, R. L.: Broadband cavity ring-down spectroscopy, in: Cavity ring-down Spectroscopy: Techniques and Applications, edited by: Berden, G. and Engeln, R., Blackwell Publishing, 2009.

Ball, S. M., Hollingsworth, A. M., Humbles, J., Leblanc, C., Potin, P., and McFiggans, G.: Spectroscopic studies of molecular iodine emitted into the gas phase by seaweed, Atmos. Chem. Phys. Discuss., 9, 26329-26376, 2009,

http://www.atmos-chem-phys-discuss.net/9/26329/2009/.

Bitter, M., Ball, S. M., Povey, I. M., and Jones, R. L.: A broadband cavity ringdown spectrometer for in-situ measurements of atmospheric trace gases, Atmos. Chem. Phys., 5, 2547-2560, 2005, http://www.atmos-chem-phys.net/5/2547/2005/.

Bloss, W. J., Lee, J. D., Johnson, G. P., Sommariva, R., Heard, D. E., Saiz-Lopez, A., Plane, J. M. C., McFiggans, G., Coe, H., Flynn, M., Williams, P. I., Rickard, A., and Fleming, Z.: Impact of Halogen Monoxide Chemistry upon Boundary Layer $\mathrm{OH}$ and $\mathrm{HO}_{2}$ concentrations at a Coastal Site, Geophys. Res. Lett., 32(6), L06814, doi:10.1029/2004GL022084, 2005.

Bloss, W. J., Lee, J. D., Heard, D. E., Salmon, R. A., Bauguitte, S. J.-B., Roscoe, H. K., and Jones, A. E.: Observations of $\mathrm{OH}$ and $\mathrm{HO}_{2}$ radicals in coastal Antarctica, Atmos. Chem. Phys., 7, 4171-4185, 2007, http://www.atmos-chem-phys.net/7/4171/2007/.
Braud, J.-P.: Etude de quelques paramgraveé tres écologiques, biologiques et biochimiques chez une Phaeophycacute des côtes bretonnes Laminaria ochroleuca, Revue des Travaux de l'Institut des Pêches Maritimes (ISTPM), 38, 1974.

Burkholder, J. B., Curtius, J., Ravishankara, A. R., and Lovejoy, E. R.: Laboratory studies of the homogeneous nucleation of iodine oxides, Atmos. Chem. Phys., 4, 19-34, 2004, http://www.atmos-chem-phys.net/4/19/2004/.

Buzorius, G., Rannik, Ü., Mäkelä, J. M., Vesala, T., and Kulmala, M.: Vertical aerosol particle fluxes measured by eddy covariance technique using condensational particle counter, J. Aerosol Sci., 29, 157-171, 1998.

Carpenter, L. J.: Iodine in the marine boundary layer, Chem. Rev., 103, 4953-4962, 2003.

Carpenter, L. J., Sturges, W. T., Penkett, S. A., Liss, P. S., Alicke, B., Heibestreit, K., and Platt, U.: Short-lived alkyl iodides and bromides at Mace Head, Ireland: links to biogenic sources and halogen oxide production, J. Geophys. Res., 104(D1), 1679-1689, 1999.

Carpenter, L. J., Malin, G., Küpper, F. C., and Liss, P. S.: Novel biogenic iodine-containing trihalomethanes and other short-lived halocarbons in the coastal East Atlantic, Global Biogeochem. Cy., 14, 1191-1204, 2000.

Carpenter, L. J., Hebestreit, K., Platt, U., and Liss, P. S.: Coastal zone production of IO precursors: a 2-dimensional study, Atmos. Chem. Phys., 1, 9-18, 2001,

http://www.atmos-chem-phys.net/1/9/2001/.

Dal Maso, M., Kulmala, M., Lehtinen, K. E. J., Mäkelä, J. M., Aalto, P., and O'Dowd, C. D.: Condensation and coagulation sinks and formation of nucleation mode particles in coastal and boreal forest boundary layers, J. Geophys. Res., 107(D19), 8097, doi:10.1029/2001JD001053, 2002.

Davis, D., Crawford, J., Liu, S., McKeen, S., Bandy, A., Thornton, D., Rowland, F., and Blake, D.: Potential impact of iodine on tropospheric levels of ozone other critical oxidants, J. Geophys. Res., 101, 2135-2147, 1996.

Dixneuf, S., Ruth, A. A., Vaughan, S., Varma, R. M., and Orphal, J.: The time dependence of molecular iodine emission from Laminaria digitata, Atmos. Chem. Phys., 9, 823-829, 2009, http://www.atmos-chem-phys.net/9/823/2009/.

Dorsey, J. R., Nemitz, E., Gallagher, M. W., Fowler, D., Williams, P. I., Bower, K. N., and Beswick, K. M.: Direct measurements and parameterisation of aerosol flux, concentration and emission velocity above a city, Atmos. Environ., 36, 791-800, 2002.

Edwards, G. D. and Monks, P. S.: Performance of a single-monochromator diode array spectroradiometer for the determination of actinic flux and atmospheric photolysis frequencies, J. Geophys. Res.-Atmos., 108(D16), 8546, doi:10.1029/2002JD002844, 2003.

Flanagan, R. J., Geever, M., and O'Dowd, C. D.: Direct measurements of new particle fluxes in the coastal environment, Environ. Chem., 2, 256-259, doi:10.1071/EN05069, 2005.

Furneaux, K. L., Whalley, L. K., Heard, D. E., Atkinson, H. M., Bloss, W. J., Flynn, M. J., Gallagher, M. W., Ingham, T., Kramer, L., Lee, J. D., Leigh, R., McFiggans, G. B., Mahajan, A. S., Monks, P. S., Oetjen, H., Plane, J. M. C., and Whitehead, J. D.: Measurements of iodine monoxide at a semi polluted coastal location, Atmos. Chem. Phys. Discuss., 9, 25737-25797, 2009, http://www.atmos-chem-phys-discuss.net/9/25737/2009/. 
Güsten, H., Heinrich, G., Schmidt, R. W. H., and Schurath, U.: A novel ozone sensor for direct eddy flux measurements, J. Atmos. Chem., 14, 73-84, 1992.

Güsten, H. and Heinrich, G.: On-line measurements ofo zone surface fluxes: Part I, Methodology and instrumentation, Atmos. Environ., 30, 897-909, 1996.

Heard, D. E., Read, K. A., Methven, J., Al-Haider, S., Bloss, W. J., Johnson, G. P., Pilling, M. J., Seakins, P. W., Smith, S. C., Sommariva, R., Stanton, J. C., Still, T. J., Ingham, T., Brooks, B., De Leeuw, G., Jackson, A. V., McQuaid, J. B., Morgan, R., Smith, M. H., Carpenter, L. J., Carslaw, N., Hamilton, J., Hopkins, J. R., Lee, J. D., Lewis, A. C., Purvis, R. M., Wevill, D. J., Brough, N., Green, T., Mills, G., Penkett, S. A., Plane, J. M. C., Saiz-Lopez, A., Worton, D., Monks, P. S., Fleming, Z., Rickard, A. R., Alfarra, M. R., Allan, J. D., Bower, K., Coe, H., Cubison, M., Flynn, M., McFiggans, G., Gallagher, M., Norton, E. G., O’Dowd, C. D., Shillito, J., Topping, D., Vaughan, G., Williams, P., Bitter, M., Ball, S. M., Jones, R. L., Povey, I. M., O’Doherty, S., Simmonds, P. G., Allen, A., Kinnersley, R. P., Beddows, D. C. S., Dall'Osto, M., Harrison, R. M., Donovan, R. J., Heal, M. R., Jennings, S. G., Noone, C., and Spain, G.: The North Atlantic Marine Boundary Layer Experiment(NAMBLEX). Overview of the campaign held at Mace Head, Ireland, in summer 2002, Atmos. Chem. Phys., 6, 2241-2272, 2006,

http://www.atmos-chem-phys.net/6/2241/2006/.

Hebestreit, K., Stutz, J., Rosen, D., Matveiv, V., Peleg, M., Luria, M., and Platt, U.: DOAS measurements of tropospheric bromine oxide in mid-latitudes, Science, 283, 55-57, 1999.

Hoffmann, T., O'Dowd, C., and Seinfeld, J. H.: Iodine oxide homogeneous nucleation: an explanation for coastal new particle production, Geophys. Res. Lett., 28, 1949-1952, 2001.

Hornsby, K. E., Flynn, M. J., Dorsey, J. R., Gallagher, M. W., Chance, R., Jones, C. E., and Carpenter, L. J.: A Relaxed Eddy Accumulation (REA)-GC/MS system for the determination of halocarbon fluxes, Atmos. Meas. Tech., 2, 437-448, 2009, http://www.atmos-meas-tech.net/2/437/2009/.

Jimenez, J. L., Bahreini, R., Cocker III, D. R., Zhuang, H., Varutbangkul, V., Flagan, R. C., Seinfeld, J. H., O’Dowd, C. D., and Hoffmann, T.: New particle formation from photooxidation of diiodomethane $\left(\mathrm{CH}_{2} \mathrm{I}_{2}\right)$, J. Geophys. Res., 108, 4318, doi:10.1029/2002JD002452, 2003.

Jones, C. E., Hornsby, K. E., Dunk, R. M., Leigh, R. J., and Carpenter, L. J.: Coastal measurements of short-lived reactive iodocarbons and bromocarbons at Roscoff, Brittany during the RHaMBLe campaign, Atmos. Chem. Phys., 9, 8757-8769, 2009, http://www.atmos-chem-phys.net/9/8757/2009/.

Kaltsoyannis, N. and Plane, J. M. C.: Quantum chemical calculations on a selection of iodine-containing species (IO, OIO, $\mathrm{INO}_{3}$, $(\mathrm{IO})_{2}, \mathrm{I}_{2} \mathrm{O}_{3}, \mathrm{I}_{2} \mathrm{O}_{4}$ and $\mathrm{I}_{2} \mathrm{O}_{5}$ ) of importance in the atmosphere, Phys. Chem. Chem. Phys., 10, 1723-1733, 2008.

Kramer, L. J., Leigh, R. J., Remedios, J. J., and Monks, P. S.: Comparison of OMI and ground based in situ and MAX-DOAS measurements of tropospheric nitrogen dioxide in an urban area, J. Geophys. Res., 113, D16S39, doi:10.1029/2007JD009168, 2008.

Küpper, F. C., Carpenter, L. J., McFiggans, G., Palmer, C. J., Waite, T., Woitsch, S., Boneberg, E.-M., Weiller, M., Potin, P., Butler, A., Luther III, G. W., Kroneck, P., Meyer-Klaucke, W., and Feiters, M. C.: Iodide accumulation provides kelp with an inorganic antioxidant impacting atmospheric chemistry, P. Natl. Acad. Sci., 105(19), 6954-6958, 2008.

Langridge, J. M., Ball, S. M., Shillings, A. J. L., and Jones, R. L.: A broadband absorption spectrometer using light emitting diodes for ultrasensitive, in situ trace gas detection, Rev. Sci. Instrum., 79, 123110, doi:10.1063/1.3046282, 2008.

Lee, J. D., McFiggans, G., Allan, J. D., Baker, A. R., Ball, S. M., Benton, A. K., Carpenter, L. J., Commane, R., Finley, B. D., Evans, M., Fuentes, E., Furneaux, K., Goddard, A., Good, N., Hamilton, J. F., Heard, D. E., Herrmann, H., Hollingsworth, A., Hopkins, J. R., Ingham, T., Irwin, M., Jones, C. E., Jones, R. L., Keene, W. C., Lawler, M. J., Lehmann, S., Lewis, A. C., Long, M. S., Mahajan, A., Methven, J., Moller, S. J., Mller, K., Müller, T., Niedermeier, N., O’Doherty, S., Oetjen, H., Plane, J. M. C., Pszenny, A. A. P., Read, K. A., Saiz-Lopez, A., Saltzman, E. S., Sander, R., von Glasow, R., Whalley, L., Wiedensohler, A., and Young, D.: Reactive Halogens in the Marine Boundary Layer (RHaMBLe): the tropical North Atlantic experiments, Atmos. Chem. Phys., 10, 1031-1055, 2010,

http://www.atmos-chem-phys.net/10/1031/2010/.

Leigh, R. J., Corlett, G. K., Friess, U., and Monks, P. S.: Concurrent multiaxis differential absorption spectroscopy system for the measurement of tropospheric nitrogen dioxide, Appl. Optics, 45(28), 7504-7518, 2006.

Leigh, R. J., Ball, S. M., Whitehead, J., Leblanc, C., Shillings, A. J. L., Mahajan, A. S., Oetjen, H., Dorsey, J. R., Gallagher, M., Jones, R. L., Plane, J. M. C., Potin, P., and McFiggans, G.: Measurements and modelling of molecular iodine emissions, transport and photodestruction in the coastal region around Roscoff, Atmos. Chem. Phys. Discuss., 9, 21165-21198, 2009, http://www.atmos-chem-phys-discuss.net/9/21165/2009/.

Lowe, D., Topping, D., and McFiggans, G.: Modelling multi-phase halogen chemistry in the remote marine boundary layer: investigation of the influence of aerosol size resolution on predicted gas- and condensed-phase chemistry, Atmos. Chem. Phys., 9, 4559-4573, 2009,

http://www.atmos-chem-phys.net/9/4559/2009/.

Mahajan, A. S., Oetjen, H., Saiz-Lopez, A., Lee, J. D., McFiggans, G., and Plane, J. M. C.: Reactive iodine species in a semi-polluted environment, Geophys. Res. Lett., 36, L16803, doi:10.1029/2009GL038018, 2009.

Mahajan, A. S., Oetjen, H., Lee, J. D., Saiz-Lopez, A., McFiggans, G., and Plane, J. M. C.: High bromine oxide concentrations in the semi-polluted boundary layer, Atmos. Environ., 43, 3811-3818, 2009.

Mårtensson, E. M., Nilsson, E. D., Buzorius, G., and Johansson, C.: Eddy covariance measurements and parameterisation of traffic related particle emissions in an urban environment, Atmos. Chem. Phys., 6, 769-785, 2006,

http://www.atmos-chem-phys.net/6/769/2006/.

McFiggans, G.: Marine aerosols and iodine emissions, Nature, 433(E5), 7026, doi:10.1038/nature03372, 2005.

McFiggans, G., Plane, J. M. C., Allan, B. J., Carpenter, L. J., Coe, H., and O'Dowd, C.: A modeling study of iodine chemistry in the marine boundary layer, J. Geophys. Res.-Atmos., 105, 1437114385, 2000.

McFiggans, G., Coe, H., Burgess, R., Allan, J., Cubison, M., Alfarra, M. R., Saunders, R., Saiz-Lopez, A., Plane, J. M. C., Wevill, D., Carpenter, L., Rickard, A. R., and Monks, P. 
S.: Direct evidence for coastal iodine particles from Laminaria macroalgae - linkage to emissions of molecular iodine, Atmos. Chem. Phys., 4, 701-713, 2004,

http://www.atmos-chem-phys.net/4/701/2004/.

McFiggans, G., Artaxo, P., Baltensperger, U., Coe, H., Facchini, M. C., Feingold, G., Fuzzi, S., Gysel, M., Laaksonen, A., Lohmann, U., Mentel, T. F., Murphy, D. M., O’Dowd, C. D., Snider, J. R., and Weingartner, E.: The effect of physical and chemical aerosol properties on warm cloud droplet activation, Atmos. Chem. Phys., 6, 2593-2649, 2006,

http://www.atmos-chem-phys.net/6/2593/2006/.

Nemitz, E., Gallagher, M. W., Duyzer, J. H., and Fowler, D.: Micrometeorological measurements of particle deposition velocities to moorland vegetation, Q. J. Roy. Meteorol. Soc., 128, 2281-2300, 2002.

O’Dowd, C., McFiggans, G., Creasey, D. J., Pirjola, L., Hoell, C., Smith, M. H., Allan, B. J., Plane, J. M. C., Heard, D. E., Lee, J. D., Pilling, M. J., and Kulmala, M.: On the photochemical production of new particles in the coastal boundary layer, Geophys. Res. Lett., 26, 1707-1710, 1999.

O’Dowd, C. D., Hämeri, K., Mäkelä, J. M., Pirjola, L., Kulmala, M., Jennings, S. G., Berresheim, H., Hansson, H.-C., de Leeuw, G., Kunz, G. J., Allen, A. G., Hewitt, C. N., Jackson, A., Viisanen, Y., and Hoffmann, T.: A dedicated study of new particle formation and fate in the coastal environment (PARFORCE): overview of objectives and achievements, J. Geophys. Res., 107, 8108, doi:10.1029/2001JD000555, 2002a.

O’Dowd, C. D., Jimenez, J. L., Bahreini, R., Flagan, R. C., Seinfeld, J. H., Hämeri, K., Pirjola, L., Kulmala, M., Jennings, S. G., and Hoffmann, T.: Marine particle formation by biogenic iodine emissions, Nature, 417, 632-636, 2002b.

O’Dowd, C. D., Hämeri, K., Mäkelä, J., Väkevä, M., Aalto, P., de Leeuw, G., Kunz, G. J., Becker, E., Hansson, H. C., Allen, A. G., Harrison, R. M., Berresheim, H., Geever, M., Jennings, S. G., and Kulmala, M.: Coastal new particle formation: Environmental conditions and aerosol physicochemical characteristics during nucleation bursts, J. Geophys. Res., 107(D19), 8107, doi:10.1029/2000JD000206, 2002.

Palmer, C. J., Anders, T. L., Carpenter, L. J., Küpper, F. C., and McFiggans, G.: Iodine and halocarbon response of Laminaria digitata to oxidative stress and links to atmospheric new particle production, Environ. Chem., 2(4), 282-290, 2005.

Pechtl, S., Lovejoy, E. R., Burkholder, J. B., and von Glasow, R.: Modeling the possible role of iodine oxides in atmospheric new particle formation, Atmos. Chem. Phys., 6, 505-523, 2006, http://www.atmos-chem-phys.net/6/505/2006/.

Peters, C., Pechtl, S., Stutz, J., Hebestreit, K., Hönninger, G., Heumann, K. G., Schwarz, A., Winterlik, J., and Platt, U.: Reactive and organic halogen species in three different European coastal environments, Atmos. Chem. Phys., 5, 3357-3375, 2005, http://www.atmos-chem-phys.net/5/3357/2005/.

Plane, J. M. C. and Saiz-Lopez, A.: Analytical techniques for atmospheric measurement, edited by: Heard, D. E., Blackwell, Oxford, 2006.

Pryor, S. C., Gallagher, M. W., Sievering, H., Larsen, S. E., Barthelmie, R. J., Birsan, F., Nemitz, E., Rinne, J., Kulmala, M., Grönholm, T., Taipale, R., and Vesala, T.: A review of measurement and modelling results of particle atmosphere-surface exchange, Tellus B, 60, 42-75, 2008.
Read, K. A., Mahajan, A. S., Carpenter, L. J., Evans, M. J., Faria, B. V. E., Heard, D. E., Hopkins, J. R., Lee, J. D., Moller, S. J., Lewis, A. C., Mendes, L., McQuaid, J. B., Oetjen, H., SaizLopez, A., Pilling, M. J., and Plane, J. M. C.: Extensive halogenmediated ozone destruction over the tropical Atlantic Ocean, Nature, 453, 1232-1235, 2008.

Saiz-Lopez, A. and Plane, J. M. C.: Novel iodine chemistry in the marine boundary layer, Geophys. Res. Lett., 31, L04112, doi:10.1029/2003GL019215, 2004.

Saiz-Lopez, A., Plane, J. M. C., and Shillito, J. A.: Bromine oxide in the mid-latitude marine boundary layer, Geophys. Res. Lett., 31, L03111, doi:10.1029/2003GL018956, 2004.

Saiz-Lopez, A., Plane, J. M. C., McFiggans, G., Williams, P. I., Ball, S. M., Bitter, M., Jones, R. L., Hongwei, C., and Hoffmann, T.: Modelling molecular iodine emissions in a coastal marine environment: the link to new particle formation, Atmos. Chem. Phys., 6, 883-895, 2006, http://www.atmos-chem-phys.net/6/883/2006/.

Sander, R. and Crutzen, P. J.: Model study indicating halogen activation and ozone destruction in polluted air masses transported to the sea, J. Geophys. Res., 101, 9121-9138, 1996.

Sander, R., Rudich, Y., von Glasow, R., and Crutzen, P. J.: The role of $\mathrm{Br} \mathrm{NO}_{3}$ in marine tropospheric chemistry: A model study, Geophys. Res. Lett., 26, 2857-2860, 1999.

Saunders, R. W. and Plane, J. M. C.: Formation pathways and composition of iodine ultra-fine particles, Environ. Chem., 2, 299303, 2005.

Schall, C. and Heumann, K. G.: GC determination of volatile organoiodine and organobromine compounds in Arctic seawater and air samples, Fresen. J. Anal. Chem., 346, 717-722, 1993.

Stutz, J., Hebestreit, K., Alicke, B., and Platt, U.: Chemistry of Halogen Oxides in the tropsphere: Comparison of Model Calculations with Recent Field Data, J. Atmos. Chem., 34, 65-85, 1999.

Stutz, J., Pikelnaya, O., Hurlock, S. C., Trick, S., Pechtl, S., and von Glasow, R.: Daytime OIO in the gulf of Maine, Geophys. Res. Lett., 34, L22816, doi:10.1029/2007GL031332, 2007.

Väkevä, M., Hämeri, K., and Aalto, P. P.: Hygroscopic properties of nucleation mode and Aitken mode particles during nucleation bursts and in background air on the west coast of Ireland, J. Geophys. Res.-Atmos., 107, 8104, doi:10.1029/2000JD000176, 2002.

Verhaeghe, E. F., Fraysse, A., Guerquin-Kern, J.-L., Wu, T.-D., Devés, G., Mioskowski, C., Leblanc, C., Ortega, R., Ambroise, Y., and Potin, P.: Microchemical imaging of iodine distribution in the brown alga Laminaria digitata suggests a new mechanism for its accumulation, J. Biol. Inorg. Chem., 13, 257-269, doi:10.1007/s00775-007-0319-6, 2008.

Vogt, R., Crutzen, P., and Sander, R.: A mechanism for halogen release from sea-salt aerosol in the remote marine boundary layer, Nature, 383, 327-330, 1996.

Vogt, R., Sander, R., von Glasow, R., and Crutzen, P. J.: Iodine chemistry and its role in halogen activation and ozone loss in the marine boundary layer: A model study, J. Atmos. Chem., 32, 375-395, 1999.

von Glasow, R., Sander, R., Bott, A., and Crutzen, P. J.: Modeling halogen chemistry in the marine boundary layer, 1 . Cloud-free MBL, J. Geophys. Res., 107, 4341, doi:10.1029/2001JD000942, 2002. 
Wada, R., Beames, J. M., and Orr-Ewing, A. J.: Measurement of IO radical concentrations in the marine boundary layer using a cavity ring-down spectrometer, J. Atmos. Chem., 58, 69-87, doi:10.1007/s10874-007-9080-z, 2007.

Wevill, D. J. and Carpenter, L. J.: Automated measurement and calibration of reactive volatile halogenated organic compounds in the atmosphere, The Analyst, 129(7), 634-638, doi:10.1039/b403550j, 2004.

Whalley, L. K., Furneaux, K. L., Gravestock, T., Atkinson, H. M., Bale, C. S. E., Ingham, T., Bloss, W. J., and Heard, D. E.: Detection of Iodine Monoxide Radicals in the Marine Boundary Layer using Laser Induced Fluorescence Spectroscopy, J. Atmos. Chem., 58, 19-39, 2007.

Whalley, L. K., Furneaux, K. L., Goddard, A., Lee, J. D., Mahajan, A., Oetjen, H., Read, K. A., Kaaden, N., Carpenter, L. J., Lewis, A. C., Plane, J. M. C., Saltzman, E. S., Wiedensohler, A., and Heard, D. E.: The chemistry of $\mathrm{OH}$ and $\mathrm{HO} 2$ radicals in the boundary layer over the tropical Atlantic Ocean, Atmos. Chem. Phys., 10, 1555-1576, 2010,

http://www.atmos-chem-phys.net/10/1555/2010/.
Whitehead, J. D., McFiggans, G. B., Gallagher, M. W., and Flynn, M. J.: Direct linkage between tidally driven coastal ozone deposition fluxes, particle emission fluxes and subsequent CCN formation, Geophys. Res. Lett., 36, L04806, doi:10.1029/2008GL035969, 2009.

Whitehead, J. D., McFiggans, G., Gallagher, M. W., and Flynn, M. J.: Simultaneous coastal measurements of ozone deposition fluxes and iodine-mediated particle emission fluxes with subsequent CCN formation, Atmos. Chem. Phys., 10, 255-266, 2010, http://www.atmos-chem-phys.net/10/255/2010/. 